\title{
Biobased Chemicals from
}

Conception toward Industrial

Reality: Lessons Learned and To

\section{Be Learned}

\section{Journal Article}

Author(s):

Dapsens, Pierre Y.; Mondelli, Cecilia; Pérez-Ramírez, Javier

Publication date:

2012-07-06

Permanent link:

https://doi.org/10.3929/ethz-a-010788580

Rights / license:

In Copyright - Non-Commercial Use Permitted

Originally published in:

ACS Catalysis 2(7), https://doi.org/10.1021/cs300124m

\section{Funding acknowledgement:}

134572 - A fundamental approach to the scale up of hierarchical zeolite catalysts (SNF) 140496 - Biomass to chemicals over tailored hierarchical zeolite-based catalysts (SNF) 


\title{
Bio-based chemicals from conception towards industrial
}

\section{reality: lessons learnt and to be learnt}

\author{
Pierre Y. Dapsens, Cecilia Mondelli,* and Javier Pérez-Ramírez*
}

Institute for Chemical and Bioengineering, Department of Chemistry and Applied Biosciences, ETH

Zurich, Wolfgang-Pauli-Strasse 10, CH-8093, Zurich, Switzerland.

*corresponding authors. Fax: +41 446331405.

E-mail addresses: cecilia.mondelli@.chem.ethz.ch; jpr@chem.ethz.ch 


\begin{abstract}
The development of innovative catalytic technologies to transform biomass into chemicals attracts increasing interest in both academic and industrial arenas as a means to establish a sustainable economy. This Perspective reviews the most relevant concepts developed in the field of chemo-catalytic conversion of biomass and proposes strategies for engineering the future generations of catalytic processes devoted to the production of chemicals from lignocellulose-derived compounds. We discuss (i) approaches currently followed in the selection of biomass conversion routes to chemicals, (ii) required operating conditions to process bio-derived feedstocks, (iii) design features for efficient catalysts, and, finally, (iv) emerging reactor and separation options. With regards to catalyst families, particular attention is given to zeolites in view of the promising utilization of these crystalline microporous aluminosilicates in dehydration, isomerization, retro-aldolization, and oxidation reactions, and of the potential of tailored (hierarchical and/or functionalized) zeolite-based systems to attain superior performances in the transformation of bio-based compounds. Throughout the way from idea towards industrial reality, we put forward scientific and technological aspects of the mature petrochemical industry that could be transposed or adapted to the bio-based manufacture of chemicals and indicate which knowledge will need to be developed ex novo.
\end{abstract}

Keywords: Bio-based chemicals; Sustainability; Conversion routes; Catalyst design; Tailored hierarchical zeolites; Reactors; Separation; Petrochemicals. 


\section{Setting the scene: biomass to chemicals}

Fossil feedstocks constitute essential pillars of the economy in modern society. They are the primary source of energy, accounting for three quarters of the world's energy supply. ${ }^{1}$ Moreover, the refining of crude oil ( $45 \%$ of the fossil raw materials) $)^{2}$ generates fuels and a wide variety of products that improve the quality of our everyday life. Nevertheless, due to the accelerated consumption of these limited resources and the associated rise in anthropogenic $\mathrm{CO}_{2}$ emissions, scientists have been exploring more sustainable sources of energy, fuels, and chemicals over the past 15 years. ${ }^{3,4}$ Biomass has received particular attention as it represents the only abundant source of renewable organic carbon which can reduce our reliance on fossil feedstocks for all of the three purposes. ${ }^{5}$ Biomass allows for a wide variety of chemical transformations and its more even distribution and accessibility around the world with respect to fossil reserves should set a better scenario in order to minimize price fluctuations and the raising of socio-economic conflicts. Among the various types of biomass, ${ }^{6}$ lignocellulose is regarded as the main raw material of the future biorefinery. This is essentially related to its non-edible nature, which implies no competition with food.

While the ideal concept of a biorefinery comprises a synergy between the production of fuels and chemicals, most of present research targets the conversion of biomass into biofuels. Still, although significant progress has been achieved at a lab-scale level ${ }^{7-9}$ and numerous routes proposed could be technically implemented in industry, the major hurdle for the realization of large-scale biofuels production appears to be the shortage of biomass, as recently stressed considering the case of the U.S. as representative for a worldwide situation. ${ }^{10,11}$ As illustrated in Figure 1, the annual crude oil demand in the U.S. (1 billion tons) roughly corresponds to the quantity of lignocellulosic raw material that agricultural and forest resources of the country could renewably supply. ${ }^{12}$ Nevertheless, since the carbon content in biomass is only half of that in crude oil, even considering full conversion and selectivity, two times more biomass than crude oil would be necessary to generate an equivalent amount of transportation fuels. On the other hand, the available lignocellulose could fully replace the fossil 
feedstock for the manufacture of commodity chemicals and polymers. ${ }^{10,11}$ This is not the only reason to emphasize the transformation of biomass into chemicals. More importantly, its oxygenate nature and chemical diversity render biomass a highly suitable raw material to manufacture a multitude of highadded value compounds. ${ }^{13}$

The production of oxychemicals and biomaterials as a way to mitigate the dependency on fossil sources was envisaged some 30 years ago. ${ }^{14}$ Moreover, in the first half of the $20^{\text {th }}$ century, fermentation was industrially practiced to produce a number of bulk organic alcohols and acids. ${ }^{15}$ The lower price and higher purity of petroleum derivatives determined the progressive abandonment of the enzymatic processes. Furthermore, the petrochemicals manufacture was grounded on well-implemented technologies allowing production at a larger scale. Nowadays, the need to replace petrochemicals by bio-based chemicals is becoming more and more pressing. Three main catalytic routes for biomass-tochemicals have emerged in the recent past, ${ }^{16}$ namely, gasification, pyrolysis, and hydrolysis (Figure 2). Along any of them, heterogeneous catalysis possesses a tremendous potential for rendering feasible and economic bio-based conversion processes. ${ }^{17}$

The fascination with the field has led scientists and technologists to pursue chemo-catalytic-oriented research following different strategies and objectives. The result is that recent findings, although often individually valuable, appear somehow complicated to rationalize or to categorize within the overall picture. Therefore, this Perspective targets two aims: (i) for researchers getting initiated in the field, we synthesize the most relevant concepts proposed in the vast literature and high-caliber reviews on biomass conversion to chemicals ${ }^{6,13}$ and (ii) for more experienced scientists, we delineate, on the basis of (i), key aspects for the development of catalytic processes that will help driving the emergence of future bio-based chemical factories. Our discussion covers all levels from idea towards practical application, starting with approaches and routes, spanning through conditions and catalyst design, and finishing with an analysis of emerging reactor types. With regards to catalyst design, emphasis is set on zeolites. Their use in biomass conversion to chemicals is reviewed and the potential of tailored zeolite- 
based materials uncovered. At each stage, we highlight whether knowledge acquired both at scientific and technological levels in the petrochemical industry can be extrapolated to the manufacture of biobased chemicals or if the development of new technologies specific to the conversion of bio-derived molecules is necessary.

\section{Strategies to approach the renewable chemical industry}

In the same manner as the production of petrochemicals rests on building blocks derived from fossil resources (namely, methanol, light olefins, and BTX), ${ }^{14}$ bio-based chemicals would be generated from the units building up the lignocellulose constituents (hydrolysis), from methanol obtained from biosyngas (gasification), or from selected fractions of bio-oil (pyrolysis) (Figure 2). The building blocks obtained by hydrolysis, i.e. glucose, mannose, xylose, galactose, and arabinose (from cellulose and hemicellulose), and phenolic derivatives (from lignin), preserve biomass' intrinsic chemical diversity. Furthermore, selective enzymatic routes are established to transform glucose, predominantly, into relevant $\mathrm{C}_{2}-\mathrm{C}_{6}$ classes of compounds, the so-called platform molecules. Syngas production by gasification implies the complete loss of all chemical functionalities in biomass and, additionally, poses hurdles due to the production of tars, thus being less favorable for this purpose than coal or natural gas. ${ }^{18}$ Bio-oil is obtained in a substantially straightforward manner and without lowering the original $\mathrm{O} / \mathrm{C}$ ratio of lignocellulose to a significant extent, but hundreds of constituents have to be separated in clean fractions for chemicals manufacture and this still constitutes a big challenge. Thus, as the production of chemicals emphases purity, sugars and their derived platforms are the most appealing starting molecules.

Two approaches to convert bio-derived feedstocks into high added-value chemicals can be identified: (i) the "product-targeted" approach that focuses on the replacement of petro-derived with bio-derived raw materials to generate specific end-products and (ii) the most commonly practiced "platformtargeted" approach based on the curiosity-driven exploration of selected starting molecules to produce 
any chemical. ${ }^{19}$ These two strategies are briefly summarized in the following and the respective main advantages and limitations are highlighted by means of examples.

\subsection{Product-targeted approach}

The product-targeted approach considers all possible pathways to synthesize one specific chemical from bio-based compounds. This is analogous to the traditional retro-synthetic analysis in organic chemistry, ${ }^{20}$ but, obviously, the substrates' pool must exclusively contain biomass' building blocks and the derived platform molecules. The most suitable route would be selected after a close examination of the fundamental aspects of the process, such as the catalyst's activity, selectivity, and lifetime, reactor type, energy balance, possible valorization of by-products, etc. (vide infra). As the availability and price of the starting molecules is also a relevant parameter, progress in fermentation technologies is expected to play an important role in enhancing the viability of chemo-catalytic routes.

The example of acrylic acid, a key compound in the polymer industry, nicely illustrates the producttargeted approach. ${ }^{21}$ Bio-derived acrylic acid is potentially obtained through several routes (Figure 3a, right panel). Various starting molecules, including glycerol, lactic acid, 3-hydroxypropionic acid, or ethanol, can be suitable. Based on purely chemical considerations, no pathway stems out as preferred, but all of the routes comprising one or two steps only are environmentally and energetically much more attractive than those involving more steps. In view of the constant expansion of our knowledge and advances in technology, one expects that a route originally selected for the manufacture of a bio-derived chemical might be changed, improved, or replaced in the future. Also in the petrochemical industry, different routes were originally considered and even implemented at industrial scale for one product. For example, the industrial manufacture of acrylic acid started at the beginning of the $20^{\text {th }}$ century when four commercially practiced technologies were introduced more or less simultaneously. As shown in Figure 3a (left panel), this chemical was produced from ethylene oxide (ethylene cyanohydrin process), from acetylene (Reppe process), from ethenone (propiolactone process), and from acrylonitrile. These processes were eventually abandoned due to economic and environmental reasons and, since the end of 
the 1960s, acrylic acid has been mostly produced via the catalyzed oxidation of propylene. Comparing the petro- and bio-based pathways to acrylic acid, it can be noticed that all bio-routes include different starting molecules or intermediates except for the one based on ethanol. Actually, all steps of the latter pathway are well-known reactions in the petrochemical industry (used in the manufacture of acrylic acid or other chemicals) and, accordingly, this route appears as the most favorable.

The comparison between the existing petrochemical industry and the prospective bio-based chemicals manufacture enables to discuss another important aspect that can guide the selection of the route, which is the compatibility of biomass value chains with their fossil counterparts and with existing infrastructure. This concept has been recently introduced by Vennestrøm et al., ${ }^{10}$ who proposed two different overall strategies, namely, a "drop-in strategy" and an "emerging strategy", and discussed their feasibility attending to the competitiveness with petrochemicals. The drop-in strategy corresponds to the transformation of a bio-derived molecule into an intermediate which is already obtained from fossil sources. Accordingly, it takes advantage of the existing technology in terms of catalyst, reactor, and process from a more or less advanced step of the value chain on. The emerging strategy represents a brand new route leading to a product with no correspondence in the petrochemical industry. Hence, its practical realization will benefit from the lack of competition with a petrochemical counterpart, but suffer from greater technological challenges.

In the above analysis of the acrylic acid manufacture, the route from ethanol could be classified as "drop-in", as it shares the $\beta$-lactone intermediate with the petrochemical route. On the other hand, the other routes cannot be labeled as "emerging", as the final product is not a new chemical. In the frame of a product-targeted approach, a complementary "substituting strategy" can thus be introduced to characterize the synthesis of a target chemical which already exists in the petrochemical industry through a totally independent pathway. As this strategy does not profit from the available technologies, the development of mature processes will require long-term commitment and substantial capital investment. The syntheses of ethylene glycol (EG) and adipic acid are illustrated in Figure $3 b$ as 
examples of the drop-in and substituting strategies, respectively. EG is currently produced by oxidation of ethylene to ethylene oxide, which is further hydrolyzed to the target product. A future bio-based route to bio-EG could rely on the following steps: (i) sugar building blocks are transformed into bio-ethanol via fermentation, (ii) bio-ethanol is converted into bio-ethylene through catalytic dehydration, and (iii) bio-ethylene enters the fossil chain to attain bio-EG. Nowadays, the synthesis of adipic acid comprises the hydrogenation of benzene into cyclohexane, the oxidation of the latter into a mixture of cyclohexanone/cyclohexanol (KA oil), and further oxidation by nitric acid. Bio-adipic acid can be obtained from glucose by oxidation to glucaric acid and subsequent hydrogenation of this intermediate to the desired chemical. ${ }^{22}$ While in the current approach the use of stoichiometric amounts of nitric acid generates large amounts of noxious nitrogen oxides, the benefits of the substituting strategy are the use of heterogeneous catalysts and the generation of only water as by-product. It is claimed that this new process has a real potential for industrialization. ${ }^{22}$

\subsection{Platform-molecule approach}

In the attempt to guide the emerging research in the production of bio-based chemicals, the U.S. Department of Energy released in 2004 a list of 15 basic molecules ${ }^{23}$ that can be derived from cellulose and hemicellulose and include organic acids (e.g. succinic, itaconic, fumaric, lactic, and levulinic acid), and polyols (e.g. glycerol, sorbitol, and xylitol). Recently, Bozell and Petersen ${ }^{24}$ proposed a reduction of the original list to 10 molecules (Figure 4a). The widely spread "platform-molecule" strategy aims at exploring catalytic ways for the conversion of these platform molecules into all possibly derivable high value-added chemicals.

The case of 5-hydroxymethylfurfural (5-HMF) and its derivatives serves as a good example to illustrate this approach. 5-HMF is typically obtained by acid-catalyzed dehydration of $\mathrm{C}_{6}$ basedcarbohydrates such as glucose or fructose and is an important intermediate in the manufacture of a variety of products. ${ }^{25}$ An overview of the main derivatives and their known or envisaged applications is 
presented in Figure 4b. The case of furan enables to highlight an important feature common to most of the platform molecules. As they directly derive from lignocellulosic building blocks (glucose, mannose, xylose, galactose, and arabinose) by means of fermentation or direct chemo-catalytic transformations, they do not generally have petrochemical equivalents and easily lead to new chemicals. These new routes can be defined as "emerging" based on the classification by Vennestrøm et al.. ${ }^{10}$

The platform-molecule approach is the most suited to discover molecules that can be used alternatively to those known from petrochemistry (that is with similar function but different backbone) or that exhibit novel characteristics and can enable the generation of new functional materials, thus broadening the current portfolio of chemicals and polymers. On the other hand, it might appear as less effective when the aim is developing a bio-based route to replace one specific petrochemical.

\section{Towards a greener industry: Liquid-phase conversion of biomass}

In this section, we analyze the requirements posed by the processing of biomass in terms of reaction conditions and how an optimal choice of the latter can help controlling the selectivity of the transformations. Furthermore, we discuss how the present research attempts to incorporate the principles of sustainability and green chemistry ${ }^{26}$ in the development of chemo-catalytic processes. It is important to remind that the utilization of a renewable feedstock such as biomass does not necessarily imply that the bio-based value chains introduced will be sustainable or green. For instance, the use of a harmless solvent, energy reduction, and the minimization of the waste generated should be critically evaluated.

In contrast to fossil feedstocks, the abundant presence of oxygen makes bio-derived molecules soluble in water, of low volatility, highly reactive, and prone to decomposition at a moderate-to-high temperature. Accordingly, the harsh conditions commonly applied to activate and functionalize hydrocarbons in gas-phase reactions will not be appropriate, at least at the first stages of the biomass conversion train, while liquid-phase operation at mild temperatures and pressures appears more suitable in order to control the chemical reactivity of bio-derived compounds. ${ }^{27}$ 
The dissolution of bio-based molecules requires highly polar media, which makes water the solvent of first choice. In this case, the viscous fermentation broths containing the various raw materials generated from biomass could be directly used without going through intermediate isolation and purification, thus decreasing energy consumption and waste generation. Alcohols are suitable as well. The use of supercritical water and carbon dioxide ${ }^{28}$ and of bio-derived solvents ${ }^{29-31}$ such as ethyl lactate and glycerol appears promising too. Further, ionic liquids (IL) have recently attracted much interest due to their ability to dissolve biopolymers. In particular, it has been shown that in the presence of IL, cellulose can be converted to key intermediates through a multi-step route in the same reactor, therefore overcoming the need for a prior production of the intermediate platform molecules by enzymatic routes (Figure 2). ${ }^{32,33}$ Despite their very low volatility and the recent advances in their purification, ${ }^{34}$ several drawbacks hamper the large-scale utilization of IL, such as their cost, high viscosity, and elusive information regarding toxicity, biodegradability, and modification of catalyst properties. Nevertheless, the perspective to achieve one-step conversions will certainly trigger research efforts to circumvent some of these limitations. Most of the media mentioned have lower volatility, toxicity, and flammability than those typically used in the petrochemical industry (mainly, aliphatic or aromatic hydrocarbons, often halogenated, ethers, and alcohols) and better match the requirements of green chemistry.

However, in order to enable selection among different processes, a quantitative description of their environmental footprint would be necessary. This issue has been already addressed for petrochemical processes and metrics have been introduced for this purpose in the last few decades, ${ }^{35}$ the most popular possibly being the $\mathrm{E}$ (nvironmental) factor ( $\mathrm{kg}$ of waste generated per $\mathrm{kg}$ of desired product). ${ }^{36}$ The advantage of this metric is that the calculation of the waste produced in the process takes into account the chemical yield and includes all reagents, solvents losses, process aids, and energy consumption (on a $\mathrm{CO}_{2}$ basis), although one limitation is that it neglects the nature of the solvent. Sheldon has recently indicated that this metric can be transposed to characterize bio-processes as well, but, possibly, integration with some form of life cycle assessment will be needed. ${ }^{37}$ 


\section{The core problem: catalyst design-}

Considering that more than $80 \%$ of the petrochemical processes rely on the use of heterogeneous catalysts, ${ }^{38}$ the engineering of materials played a key role in this success story. In order to place the biobased chemical industry at the same technological level, one of the major scientific challenges is the development of selective, stable, and active (in this priority order) catalysts able to convert biomass with a comparable efficiency. ${ }^{39,40}$ To this end, materials' properties, process conditions, and reactor configurations should be optimized. Nevertheless, the intrinsically different chemical properties of the molecules that have to be converted, as well as the different processing environment needed to control and preserve their reactivity pose additional requirements on the catalysts features that have to be tuned with respect to the petro-chemical scenario. These critical factors and their impact on the catalyst design have been addressed in recent reviews..$^{27,41}$

Based on these premises, is the extrapolation of catalytic technologies developed for petrochemical transformations to the conversion of bio-based compounds possible and which catalyst families appear more promising? In the last years, several catalytic systems, widely and effectively employed in the preparation of petrochemicals, have been used for transformations along the production lines of biobased chemicals. ${ }^{13,42}$ Figure 5 reports the main catalyst families, indicating the reactions catalyzed and the main benefits and drawbacks.

Metal oxides. These materials have been successfully applied in isomerization and dehydration. $\mathrm{TiO}_{2}$ and $\mathrm{ZrO}_{2}$, for example, catalyze the conversion of glucose in hot-compressed water through isomerization to fructose and further dehydration (to HMF, mainly), ${ }^{43}$ while cerium oxide shows remarkable activity and selectivity in the dehydration of 1,3-propanediol to 2-propen-1-ol. ${ }^{44}$ In spite of their typically low cost, their structural instability in polar media hinders the vast utilization of these materials. Solubilization is particularly enhanced when water under supercritical conditions is used ${ }^{45}$ as often required for dehydration reactions. Thus, metal oxides might be more suited for transformations at 
late stages of the biomass conversion chain, which involve substrates with reduced $\mathrm{O} / \mathrm{C}$ ratio and, hence, less polar solvents.

Metal oxide-supported metals. These systems have shown good performances in hydrogenation, oxidation, and C-C bond breaking of cellulose and platform molecules as well as subsequent chemical intermediates. ${ }^{46}$ For instance, Taarning et al. ${ }^{47}$ report the formation of methyl lactate with $72 \%$ selectivity by oxidation of 1,2-propanediol over $1 \mathrm{wt} . \% \mathrm{Au} / \mathrm{TiO}_{2}$. The aqueous-phase oxidation of glucose to gluconic or glucaric acid is respectively obtained with high yields over $\mathrm{Au} / \mathrm{Al}_{2} \mathrm{O}_{3}{ }^{48}$ and supported $\mathrm{Pt}$ catalysts. ${ }^{22} \mathrm{Pt} / \mathrm{Al}_{2} \mathrm{O}_{3}$ has been reported to be highly active in the dehydrationhydrogenation of cellulose into sugar alcohols such as sorbitol and mannitol. ${ }^{49}$ The low water tolerance of metal oxides mentioned above would imply their unfavorable use as carriers for metals. At present, the information reported with regards to the stability of metal oxide-supported metals is very limited. Nevertheless, the $\mathrm{Au} / \mathrm{Al}_{2} \mathrm{O}_{3}$ catalyst employed for the oxidation of glucose to gluconic acid seems to offer encouraging durability. No loss in activity or selectivity was in fact observed during 70 days of continuous operation. ${ }^{48}$

Carbon-supported metals. Carbon-supported metals attained encouraging results in hydrogenation, hydrogenolysis, and oxidation. ${ }^{50}$ As an example, $\mathrm{Pd} / \mathrm{C}$ enabled the formation of glycerate by oxidation of glycerol under basic conditions with high selectivity (77\%), ${ }^{51}$ while $\mathrm{Ru} / \mathrm{C}$ has been recently described as an efficient catalyst in the hydrogenolysis of xylitol to ethylene glycol. ${ }^{52}$ Carbons seem to represent a suitable alternative to metal oxides to support metals, as they are highly resistant in acidic and alkaline media, display specific surface areas up to $3000 \mathrm{~m}^{2} / \mathrm{g}$, and have a relatively low cost. Moreover, the carbon can be burnt off the catalyst after use, thus enabling to recover the active phase loaded, which is particularly advantageous in case of expensive metals. On the other hand, the heterogeneity of the surface (i.e. nature and number of oxygenated surface chemical species) and the presence of nonordered and small-size pores negatively affect the dispersion of the active phase. ${ }^{53}$ This, along with the lack of mechanical strength, makes the commercial application of conventional carbons rather 
unattractive, while the use of carbon replica of ordered mesoporous materials (MCM-41, MCM-48, or SBA-15), which offer well-ordered and tunable mesoporosity, is indicated as promising. ${ }^{54}$ Nonetheless, even if these materials demonstrated superior properties, their complex and expensive synthesis would likely hamper a broad utilization.

Acid-functionalized mesoporous materials. In view of their strong acidity, high specific area, and well-ordered mesoporosity, acid-functionalized mesoporous materials are able to catalyze esterification, hydrolysis, and dehydration reactions attaining high conversions and selectivities. ${ }^{55}$ For instance, sulfonic acid-functionalized MCM-41 is reported to dehydrate xylose into furfural with a selectivity of $82 \%$ at $91 \%$ conversion. ${ }^{56}$ Recent work by Diaz et al. suggests that superior performances can be attained by selecting materials with adequate porous characteristics and controlling the strength and distribution of the functional groups grafted. ${ }^{57}$ In particular, the authors report a $\mathrm{MCM}-41-\mathrm{SO}_{3} \mathrm{H}$ catalyst featuring a specific balance between lipophilic and hydrophilic species that selectively attains the monoesterification of glycerol with fatty acids. Owing to the presence of mesoporosity, it is expected that these materials could be beneficial for the processing of bulky substrates. Nevertheless, due to their amorphous nature, the hydrothermal and mechanical stability of these solids is typically limited, which may lead to disintegration of the structure within a few hours upon use in aqueous solutions. ${ }^{58}$

Ion-exchange resins. Ion-exchange resins such as Amberlyst ${ }^{\circledR}, \mathrm{Nafion}^{\circledR}$, and Dowexes ${ }^{\circledR}$ have been for long employed for hydrolysis and esterification and more recently applied for alkylation or deformylation. ${ }^{59}$ Still, their moderate thermal stability (e.g. up to $280^{\circ} \mathrm{C}$ for Nafion ${ }^{\circledR}$ - NR50, $190^{\circ} \mathrm{C}$ for Amberlyst $70^{\circledR}$, and $150^{\circ} \mathrm{C}$ for Dowexes) strongly restricted the utilization of this catalyst family in petrochemistry. On the other hand, their high water compatibility and strong acidity, as well as the possibility to generate materials with high surface area and improved microstructure, point to a successful application of resins to the liquid-phase processing of biomass derivatives at mild temperatures. Nafion 117 is reported to dehydrate xylose to furfural with considerable yield (60\%), and to maintain the original activity level upon utilization in several catalytic runs. ${ }^{60}$ The main drawbacks of 
acidic resins are poisoning by bases, such as amines, and poor resistance to abrasion, detrimental for use in stirred reactors. ${ }^{61}$

Zeolites and zeolite-supported metals. Their high specific area, strong acidity, remarkable (hydro)thermal stability, and the presence of pores of molecular dimensions rendered zeolites hegemonic catalysts in the petrochemical industry. These characteristics set a highly promising basis for the adaptation of this catalyst family to bio-based chemicals production. Furthermore, exploration of zeolites for this purpose has already attracted research and produced encouraging results. The use of Lewis acidic zeolites for the conversion of sugars to lactates and furans, glycerol to acrolein, and terpenes to selected starting materials for the manufacture of fine chemicals has been recently reviewed. ${ }^{62}$ Herein, we present a broader overview of the main zeolites and zeotypes used and the most prominent catalytic data obtained in the transformation of various platform molecules in liquid phase and under mild conditions (below $150^{\circ} \mathrm{C}$ ). This information is collected in Table 1 . We do not aim at giving exhaustive reference to every zeolite-catalyzed reaction reported in the field of biomass to chemicals, but rather to highlight the most prominent examples which demonstrate the potentially wide applicability of these catalysts. So far, zeolites of BEA, MFI, FAU, MOR, and FER frameworks have successfully catalyzed dehydration, isomerization, retro-aldolization, oxidation, and hydrogenation reactions. The capability of zeolites to perform a broad spectrum of transformations descends from their structural versatility. This involves both the availability of a large number of frameworks featuring different pore shape, size, and connectivity, and the possibility to modify existing and/or insert new types of catalytic centers, by means of well-established methods, into a specific zeolite structure.

As expected from their strong Brønsted acidity, zeolites are able to accomplish dehydration reactions, such as fructose to 5-HMF or xylose to furfural, with remarkable-to-very high conversion. Some of these catalyst are equaled or surpassed only by certain resins ${ }^{60,80}$ and sulfonated mesoporous silica $^{56}$ activity-wise. Remarkably, the selectivity of the zeolite-catalyzed processes can be modulated by the specific porous characteristics of different frameworks (BEA, MOR, FAU, and MFI). Thus, at present, 
H-mordenite dominates the dehydration scene offering the highest selectivities to the desired products (90\% in both cases) among all catalyst types.

With regard to the structural modifications, Lewis acid sites can be introduced by exchanging framework aluminum or silicon atoms with other heteroatoms. The presence of this type of acidity has been demonstrated important for isomerization and retro-aldolization reactions. A very remarkable example is the isomerization of dihydroxyacetone (DHA) to lactic acid (LA) which is realized with full conversion and a selectivity of $90 \%$ over Sn-beta (Table 1). ${ }^{66}$ Still, although the nature of the active sites is crucial, the micropore characteristics seem to play a role in order to drive the selectivity towards the desired product as well. Thus, the incorporation of tin into the MFI framework (Sn-silicalite) attained lower LA selectivity $(66 \%) .{ }^{73}$ In the case of the isomerization of glucose into fructose, the selectivity dependency on the framework structure is stronger, and, due to the larger size of the substrate, the conversion level is also affected. Sn-silicalite converts glucose at very low extent (9\%) with moderate selectivity $(44 \%),{ }^{73}$ while much more relevant data $(56 \%$ conversion, $75 \%$ selectivity) are obtained using Sn-beta. ${ }^{63,64}$ It is worth noting that also the Sn-free zeolites H-MOR, H-ZSM-5, and H-Y exhibit significant performances in the isomerization of DHA to LA (99\% conversion, 39, 22, and $71 \%$ selectivity, respectively), indicating that zeolites purely containing $\mathrm{Si}$ and $\mathrm{Al}$ can be active for this reaction. ${ }^{72}$ In this respect, extra-framework aluminum sites should be responsible for the activity. With regards to retro-aldolization Sn-beta achieves full conversion in most cases and selectivities ranging between 44 and $64 \%$, depending on the starting sugar (Table 1).

By ion exchange, metal ions with redox properties can also be inserted in the material. Titaniumcontaining zeolites, such as Ti-Y and TS-1, have been reported to catalyze the oxidation of glucose to gluconic acid, although the conversion and selectivity reported are rather low. Supported noble metals (e.g. Au) have demonstrated to perform much better in this reaction, but such catalysts typically are more costly. ${ }^{81}$ Although the amount of titanium in the framework FAU is not reported, the selectivity is double $(28 \%)$ using Ti-Y with respect to TS-1 $(12 \%) .{ }^{74}$ In view of the clear impact of the porous 
structure, it is expected that zeolites can be improved to reach more significant conversion and selectivity levels.

The deposition of metals in form of nanoparticles onto the external surface of zeolites enables to generate catalysts featuring both strong acid and redox sites. The use of such bifunctional material is advantageous to perform a two-step reaction in one pot. For instance, $\mathrm{Pt} / \mathrm{NaY}$ is reported as a highly active and selective catalyst for the conversion of glycerol to 1,2-propanediol, which involves the acidcatalyzed dehydration of the reactant to hydroxyl acetone and the metal-catalyzed hydrogenation of the latter to desired product (Table 1). This reaction can be performed even in the absence of external hydrogen supply, since platinum enables its in situ production through the aqueous-phase reforming of a small amount of glycerol. ${ }^{79}$

When applicable, information on catalyst productivity and reusability, two aspects that become particularly relevant in view of the implementation of the processes developed at an industrial scale, has been gathered in Table 1. Concerning the former, the substrate concentrations in the feed, with the exception of the isomerization of glucose to fructose, were generally rather low (below 10 wt.\%). An economically viable and environmentally-friendly process would require operation with more concentrated solutions. This implies that more efforts should be put in ensuring that catalysts are able to process highly viscous solutions without suffering from excessive mass transfers limitations and active site blocking/deactivation via depositions of side products, for instance. With regards to catalyst reusability, little information is available. Only for Sn-beta and Ti-Y it was confirmed that the catalyst could be employed with no appreciable loss in activity for 3-6 runs. Further research work should try to put more emphasis on this essential aspect too.

Along our discussion of activity data, we have encountered conversion and, most importantly, selectivity figures that are only moderate or even rather low. We would like to stress that these less attractive examples were included in order to underline the ample margin for improving catalysts and reaction conditions. The selectivity values reported are state-of-the-art for zeolites and all other catalyst 
classes. Isolated exceptions have been pointed out along the discussion. We think that significant advances could be achieved via rational catalyst design in zeolite-based conversion of biomass, as explained hereon. Besides the modifications mentioned above, a wide array of treatments ${ }^{82-85}$ has recently become available that enables to obtain tailored zeolites with superior properties. Herein, we focus on the post-synthetic modification options (Figure 6), as the scalability, simplicity, and versatility of these methods offer real potential for implementation for industrial manufacture of modified zeolites. ${ }^{86}$ Sequential desilication (by base leaching) and dealumination (by acid treatment) mediated by the use of so-called pore directing agents allow to obtain hierarchically-structured zeolites which couple the original microporosity with an auxiliary interconnected mesopore network. ${ }^{87}$ These mesoporous zeolites retain the intrinsic features of the parent zeolites, but benefit from higher accessibility. Remarkably, the mesoporous surface and pore size distribution can be tuned by simple adjustments of parameters such as the concentration of the reactants or the temperature. ${ }^{87}$ Most of the zeolite frameworks widely used in the petrochemical industry (FAU, MFI, MOR, BEA, MTW, AST, FER, MWW, IFR, STF, CHA, TON) can be prepared in mesoporous form at present. Although literature does not report a full compositional investigation for each zeolite, recent studies performed on ZSM-5 and Y/USY ${ }^{88}$ suggest that any zeolite can be obtained in hierarchical form. Zeolite $\mathrm{Y}$ is particularly interesting in view of its prominent role in petrochemistry, the deep knowledge on this material, and especially because its synthesis does not require the use of an expensive template, as in the case of all other zeolites. The textural properties of modified zeolite Y resemble those of mesoporous MCM-41, but the aluminosilicate displays better intrinsic acidity, selectivity, and (hydro)thermal stability. Additionally, simultaneously with the textural alteration, modification of the native acid/base properties of the zeolite can be achieved. In particular, the number, type (Brønsted or Lewis), and distribution of sites can be tuned.

The creation of a mesoporous surface paves the way for further possibilities (Figure 6). The use of a hierarchical zeolite as carrier for a metal phase is expected to be very favorable for obtaining a bifunctional material with superior properties in view of the availability of an even larger external 
surface onto which the metal phase can be deposited, thus achieving higher dispersion ${ }^{89}$, and of the closer proximity of the metal and acid/base sites in the solid with respect to the parent zeolite. Another interesting alternative is the grafting of organic functionalities over the mesoporous area freshly developed. This might include the introduction of sulfonic acid groups, ${ }^{90}$ or the heterogeneization of homogeneous metal complexes, ${ }^{91-93}$ which currently attracts much interest as a way to combine the intrinsically outstanding stereoselectivity of these catalysts with the ease of separation of a solid material.

Catalytic data attained with the use of hierarchically-structured materials for the conversion of fossilderived compounds have indicated enhanced activity, reduced deactivation, and improved selectivity. ${ }^{94-}$ ${ }^{96}$ Initial results obtained using conventional and post-synthesis modified H-ZSM-5 and H-USY zeolites in the isomerization of DHA into LA provide a first tangible evidence that tailored zeolites could be successfully upgraded for the preparation of bio-based chemicals. Though of preliminary nature, we believe these findings important to strengthen our perspective. Figure 7 depicts the DHA conversion (green bars) and LA selectivity (blue bars) after $6 \mathrm{~h}$ reaction. Conventional H-ZSM-5 and H-USY zeolites exhibit remarkable activity and appreciable selectivity. The activity of the modified zeolites results almost unaltered. The small size of the DHA molecule, and, thus, the low benefit on reducing the diffusion limitations, might explain this. Clearer positive effects should be obtained when converting substrates of larger size. Remarkably, for both the frameworks, the modified zeolites attain ca. 50\% higher selectivity to LA with respect to the parent samples (81\% versus $55 \%$ for ZSM-5 zeolites and $71 \%$ versus $53 \%$ for USY zeolites). It is worth noting that the selectivity to LA obtained with mesoporous H-ZSM-5 surpasses by far literature data for conventional ZSM-5 (32\%) and other conventional zeolites $^{72}$ and approaches the selectivity of the Sn-beta zeotype (90\%, Table 1). An accurate speciation and quantification of the acid sites will enable to understand if and to which extent extra-framework $\mathrm{Al}$ species were already present in the parent zeolites and if their amount was increased upon desilication, as expected. As the synthesis of zeotypes such as the mentioned Sn-beta is 
long and the presence of a metal makes it costly, ${ }^{72}$ tuning the Lewis acidity by varying the aluminum content and distribution via post-synthetic treatments appears much simpler, faster, and more economical in view of a practical application. The establishment of structure-property-function relationships will indicate which combination of modifications will render optimized catalysts.

\section{Towards the process}

Describing the detailed configuration of a bio-based chemical factory is premature. Nevertheless, as the success of any industrial process finds its origin in the optimal synergy between catalyst and reactor, we would like to analyze which reactor concepts appear suited to drive the liquid-phase preparation of bio-based chemicals from lab-scale towards practical application. Furthermore, as selectivity constitutes a critical aspect in the conversion of bio-based compounds, other unit operations such as separations will be addressed too.

Virtually all reactions so far studied at an academic level are carried out in simple vessels such as round-bottomed glass-flasks or stainless steel autoclaves. ${ }^{74,79}$ Consequently, slurry reactors operated in batch mode seem to be the natural choice in the design of a process. These reactors are typically used in the low-volume pharmaceutical and fine-chemicals industries. On the opposite, the high-volume production of bulk petrochemicals relies on the use of gas-phase processes under continuous operation. ${ }^{97}$ The paradox imposed by bio-derived molecules is the necessity to produce commodity chemicals in the liquid phase. In order to achieve this goal, we expect that a transition towards operation in slurry reactors in continuous mode will be necessary in the future. Although we believe that slurry reactors will be predominantly employed, reactor designs based on an immobilized catalyst, such as the trickle-bed reactor, might receive increased attention in view of the easier recovery of the solid after use. Still, as structured catalysts are applied in these configurations, the latter should be carefully optimized to ensure efficient mass and heat transfer. For some applications, monoliths ${ }^{98}$ could gain interest as they offer the possibility to have a fixed bed and retain high effectiveness. Additionally, recently proposed 
reactor concepts such as the spinning disc reactor $(\mathrm{SDR})^{99}$ and the oscillatory flow reactor $(\mathrm{OFR}),{ }^{100}$ operated in continuous mode, are interesting ideas. Thanks to the large centrifugal forces generated, the SDR is characterized by increased heat transfer coefficients, which renders it extremely suitable for highly exothermic processes. This reactor could represent a convenient alternative to stirred tank reactors, which suffer from poor mixing in viscous environments and complicated temperature control, for polymerizations. On the other hand, the OFR would be more appropriate choice for reactions which require long times, as its combination of baffles and oscillatory motion leads to increased heat and mass transfer and plug flow behavior. Case by case assessment of the overall effect of parameters such as reaction kinetics and enthalpy, temperature, viscosity, catalyst characteristic length and porosity, and substrate shape and size, will indicate the optimal reactor concept.

Due to the highly functionalized nature of bio-derived molecules, one crucial issue in their transformation is selectivity. Therefore, the development of more efficient and targeted separation methods nowadays receives much interest. In this respect, distillation, extraction, adsorption with molecular sieves, filtration, crystallization, and osmosis hold great promise and have been thoroughly reviewed by Huang et al. ${ }^{101}$ A significant example is the extractive separation of an aqueous solution of 3-hydroxypropionic acid (non-converted starting platform molecule) and acrylic acid (desired dehydration product). Separation is attained by addition of an accurately selected extrinsic phase (ethyl acetate) for which the two molecules have different partitioning coefficients. ${ }^{102}$ Purification of the recovered acrylic acid could be performed by fractional crystallization. In the process described, a salt (e.g. sodium chloride) is added which eliminates the eutectic point existing between water an acrylic acid and, thus, enables its selective crystallization upon decrease of the temperature. ${ }^{103}$ This method is claimed to constitute a good alternative to distillation, which suffers from limited yields due to partial polymerization of acrylic acid.

Recently, research efforts have determined the appearance of a few highly attractive systems, in which "reaction" and "separation" are integrated in the same unit (so-called "hybrid process"). One 
such example is the biphasic reactor proposed by Román-Leshkov et al. ${ }^{80,104}$ for the catalytic dehydration of fructose to HMF (Figure 8a). The desired product forms in the aqueous phase and is continuously extracted into a separation-friendly organic phase. This procedure attains to minimize the occurrence of side reactions in water and, thus, boost the HMF yield of the process. According to a recent analysis by Torres et al., ${ }^{105}$ the bio-based HMF manufactured in a process based on this biphasic reactor would cost only about twice as much as petro-derived HMF. The versatility of this system has been demonstrated through the utilization of various feedstock such as glucose or cellulose. ${ }^{106}$ It has been also shown that biphasic reactors can be combined in series and with intermediate separation and reaction units to achieve multi-steps or cascade reactions, such as the conversion of xylose into levulinic acid. $^{107}$

A few years earlier, Kröger et al. ${ }^{108}$ reported a reactor system which could be considered as an evolution of the biphasic reactor by Román-Leshkov et al.. The main difference in the design is the additional presence of a PTFE-membrane separating the aqueous and organic phase into two distinct compartments, whose porosity is chosen to disable the transfer of fructose from the aqueous to the organic phase (Figure $8 \mathrm{~b}$ ). This makes it possible to combine the dehydration of fructose into HMF with a further oxidation step that leads to 2,5-furandicarboxylic acid (FDCA). Moreover, the selectivity of the process is high thanks to the removal of the intermediate product (HMF) by transfer through the membrane and the preservation of fructose from degradation by oxidation, as it constrained into the aqueous phase.

Future efforts might also be focused to develop tailored membrane reactors. This concept has been already proven in the area of bio-catalytic biomass conversion. Arora et al. ${ }^{109}$ have in fact developed a "separative bioreactor", which enables the continuous enzymatic production and recovery of organic acids, owing to the immobilization of the biocatalyst on an ion-exchange resin which also functions as membrane. With regards to chemo-catalytic transformations, we think that zeolites, which combine catalytic and molecular-sieve properties, ${ }^{110}$ could be highly suited for this purpose. 


\section{Conclusions and outlook}

Although the market of bio-derived chemicals is still in its infancy, the progressive shift towards biobased chemical factories starts to become an industrial reality. Aiming at a faster and effective transition, key aspects to engineer suitable chemo-catalytic routes for the production of bio-derived chemicals have been herein discussed, based on the most relevant concepts proposed in the literature of biomass-to-chemicals and emphasizing if the knowledge and technologies developed in the petrochemical industry can be transposed or if new expertise has to be built. The conversion of biomass will mainly follow two different strategies, leading to bio-based chemicals that replace existing petrochemicals, either by generation of intermediates of fossil value chains or through totally alternative pathways, or to new products. The routes belonging to the former path might be more easily established as they can benefit of existing technologies. Generally, the use of mild processing conditions and liquid polar media should be preferred to ensure optimal control over the reactivity of bio-derived molecules, enable one-pot reactions, and guarantee environmental friendliness.

Among the existing catalyst families, carbon-supported metals and resins seem to offer good perspectives for application to biomass conversion. Still, we believe that zeolite-based catalysts have higher potential for upgrading in the future bio-based chemical industry, owing to their intrinsic properties and especially in view of their extraordinary versatility. A very preliminary but perceptible step in this direction has been shown based on the performance of modified zeolites.

Towards a practical application, research should "refresh" traditional reactor concepts and intensify efforts to integrate reaction and separation in a single unit. 


\section{References}

(1) REN21 (2010). Renewables 2010 Global Status Report. Paris: REN21 Secretariat. http://www.ren21.net/Portals/97/documents/GSR/REN21_GSR_2010_full_revised\%20Sept2010 .pdf (accessed February 2012).

$\begin{array}{llllll}\text { (2) BP } & \text { Statistical } & \text { Review } & \text { of } & \text { World } & \text { Energy }\end{array}$ http://www.bp.com/liveassets/bp_internet/russia/bp_russia_english/STAGING/local_assets/dow nloads_pdfs/s/Stat_Rev_2006_eng.pdf (accessed February 2012).

(3) Pacala, S.; Socolow, R. Science 2004, 305, 968-972.

(4) Armaroli, N.; Balzani, V. Angew. Chem., Int. Ed. 2007, 46, 52-66.

(5) Ragauskas, A. J.; Williams, C. K.; Davison, B. H.; Britovsek, G.; Cairney, J.; Eckert, C. A.; Frederick Jr., W. J.; Hallett, J. P.; Leak, D. J.; Liotta, C. L.; Mielenz, J. R.; Murphy, R.; Templer, R.; Tschaplinski, T. Science 2006, 311, 484-489.

(6) Chheda, J. N.; Huber, G. W.; Dumesic, J. A. Angew. Chem., Int. Ed. 2007, 46, 7164-7183.

(7) Huber, G. W.; Chheda, J. N.; Barrett, C. J., Dumesic, J. A. Science 2005, 308, 1446-1450.

(8) Huber, G. W.; Iborra, S.; Corma, A. Chem. Rev. 2006, 106, 4044-4098.

(9) Kunkes, E. L.; Simonetti, D. A.; West, R. M.; Serrano-Ruiz, J. C.; Gärtner, C. A.; Dumesic, J. A. Science 2008, 322, 417-421.

(10) Vennestrøm, P. N. R.; Osmundsen, C. M.; Christensen, C. H.; Taarning, E. Angew. Chem., Int. Ed. 2011, 50, 10502-10509.

(11) Dodds, D. R.; Gross, R. A. Science 2007, 318, 1250-1251.

(12) U.S. Department of Energy http://www1.eere.energy.gov/biomass/pdfs/final_billionton_vision_report2.pdf (accessed February 2012).

(13) Corma, A.; Iborra, S.; Velty, A. Chem. Rev. 2007, 107, 2411-2502.

(14) Lipinsky, E. S. Science 1981, 212, 1465-1471. 
(15) Ng, T. K.; Busche, R. M.; McDonald, C. C.; Hardy, R. W. F. Science 1983, 219, 733-740.

(16) Alonso, D. M.; Bond, J. Q.; Dumesic, J. A. Green Chem. 2010, 12, 1493-1513.

(17) Climent, M. J.; Corma, A.; Iborra, S. Green Chem. 2011, 13, 520-540.

(18) Prins, M. J.; Ptasinski, K. J.; Janssen, F. J. J. G. Energy 2007, 32, 1248-1259.

(19) Gallezot, P. Green Chem. 2007, 9, 295-302.

(20) Corey, E. J. Chem. Soc. Rev. 1988, 17, 111-133.

(21) Weissermel, K.; Harpe H. -J. Industrial organic chemistry, $4^{\text {th }}$ ed.; Wiley-VCH Verlag, Weinheim, Germany, 2003, pp. 291-294.

(22) Boussie, T. R.; Dias, E. L.; Fresco, Z. M.; Murphy, V. J.; Shoemaker, J.; Archer, R.; Jiang, H. U.S. Patent 0317823, 2010.

(23) Werpy, T., Petersen, G., Eds.; Top Value Added Chemicals From Biomass; Report for Office of Biomass Program, U.S. Department of Energy; U.S. Department of Commerce, National Technical Information Service: Springfield, VA, 2004; Vol. 1, pp. 1-76.

(24) Bozell, J. J.; Petersen, G. R. Green Chem. 2010, 12, 539-554.

(25) Rosatella, A. A.; Simeonov, S. P.; Frade, R. F. M.; Afonso, C. A. M. Green Chem. 2011, 13, 754-793.

(26) Anastas, P. T.; Warner, J. C. Green Chemistry: Theory and Practice, Oxford University Press: New York, 1998, p. 30.

(27) Serrano-Ruiz, J. C.; Luque, R.; Sepúlveda-Escribano, A. Chem. Soc. Rev. 2011, 40, 5266-5281.

(28) Savage, P. E. J. Supercrit. Fluids 2009, 47, 407-414.

(29) Jessop, P. G. Green Chem. 2011, 13, 1391-1398.

(30) Díaz-Álvarez, A. E.; Francos, J.; Lastra-Barreira, B.; Crochet, P.; Cadierno, V. Chem. Commun. 2011, 47, 6208-6227.

(31) Pereira, C. S. M.; Silva, V. M. T. M.; Rodrigues, A. E. Green Chem. 2011, 13, 2658-2671.

(32) Schoevaart, R.; Kieboom, T. Top. Catal. 2004, 27, 3-9. 
(33) Zhang, Q.; Zhang, S.; Deng, Y. Green Chem. 2011, 13, 2619-2637.

(34) Dibble, D. C.; Li, C.; Sun, L.; George, A.; Cheng, A.; Persil Çetinkol, Ö.; Benke, P.; Holmes, B.

M.; Singh, S.; Simmons, B. A. Green Chem. 2011, 13, 3255-3264.

(35) Dunn, P. J. Chem. Soc. Rev. 2012, 41, 1452-1461.

(36) Sheldon, R. A. Chem. Ind. (London, U. K.) 1992, 903-906.

(37) Sheldon, R. A. Catal. Today 2011, 167, 3-13.

(38) Thomas, J. M. Angew. Chem., Int. Ed. 2009, 48, 3390-3392.

(39) Gallezot, P. ChemSusChem 2008, 1, 734-737.

(40) Shanks, B. H. Ind. Eng. Chem. Res. 2010, 49, 10212-10217.

(41) Rinaldi, R.; Schüth, F. Energy Environ. Sci. 2009, 2, 610-626.

(42) Egeblad, K.; Rass-Hansen, J.; Marsden, C. C.; Taarning, E.; Christensen, C. H. Catalysis 2009, $21,13-50$.

(43) Watanabe, M.; Aizawa, Y.; Iida, T.; Nishimura R.; Inomata, H. Appl. Catal., A 2005, 295, 150156.

(44) Sato, S.; Takahashi, R.; Sodesawa, T.; Honda, N.; Shimizu, H. Catal. Commun. 2003, 4, 77-81.

(45) Ziemniak, S. E. J. Solution. Chem. 1992, 21, 745-760.

(46) Barrett, C. J.; Chheda, J. N.; Huber, G. W.; Dumesic, J. A. Appl. Catal., B 2006, 66, 111118.

(47) Taarning, E.; Madsen, A. T.; Marchetti, J. M.; Egeblad, K.; Christensen, C. H. Green Chem. 2008, $10,408-414$.

(48) Thielecke, N; Aytemir, M.; Prüsse, U. Catal. Today 2007, 121, 115-120.

(49) Fukuoka, A.; Dhepe, P. L. Angew. Chem., Int. Ed. 2006, 45, 5161-5163.

(50) Gallezot, P.; Nicolaus, N.; Fleche, G.; Fuertes, P.; Perrard, A. J. Catal. 1998, 180, 51-55.

(51) Garcia, R.; Besson, M.; Gallezot, P. Appl. Catal., A 1995, 127, 165-176.

(52) Sun, J.; Liu, H. Green Chem. 2011, 13, 135-142. 
(53) Prado-Burguete, C.; Linares-Solano, A.; Rodriguez-Reinoso, F.; Salinas-Martínez de Lecea, C.

J. Catal. 1989, 115, 98-106.

(54) Kobayashi, H.; Komanoya, T.; Hara, K.; Fukuoka, A. ChemSusChem 2010, 3, 440-443.

(55) Siegers, G.; Martinola, F. Int. Sugar. J. 1985, 87, 23-53.

(56) Dias, A. S.; Pillinger, M.; Valente A. A. J. Catal. 2005, 229, 414-423.

(57) Perez-Pariente, J.; Diaz, I.; Mohino, F.; Sastre, E. Appl. Catal., A 2003, 254, 173-188.

(58) Kim, J. M.; Ryoo, R. Bull. Korean Chem. Soc. 1996, 17, 66-68.

(59) Harmer, M. A.; Sun, Q. Appl. Catal., A 2001, 221, 45-62

(60) Lam, E.; Majid, E.; Leung, A. C. W.; Chong, J. H.; Mahmoud, K. A.; Luong, J. H. T. ChemSusChem 2011, 4, 535-541.

(61) Gates, B. C. Handbook of Heterogeneous Catalysis. Wiley-VCH Verlag, Weinheim, Germany, 2008, pp. 278-285.

(62) Taarning, E.; Osmundsen, C. M.; Yang, X.; Voss, B.; Andersen, S. I.; Christensen, C. H. Energy Environ. Sci. 2011, 4, 793-804.

(63) Moliner M.; Román-Leshkov, Y.; Davis, M.E. Proc. Nat. Acad. Sci. 2010, 107, 6164-6168.

(64) Román-Leshkov, Y.; Moliner, M.; Labinger, J. A.; Davis, M. E. Angew. Chem., Int. Ed. 2010, 49, 8954-8957.

(65) Choudhary, V.; Pinar, A. B.; Sandler, S. I.; Vlachos, D. G.; Lobo, R. F. ACS Catal. 2011, 1, 1724-1728.

(66) Taarning, E.; Saravanamurugan, S.; Holm, M. S.; Xiong, J. M.; West, R. M.; Christensen, C. H. ChemSusChem 2009, 2, 625-627.

(67) Holm, M. S.; Saravanamurugan, S.; Taarning, E. Science 2010, 328, 602-605.

(68) Holm, M. S.; Pagán-Torres, Y. J.; Saravanamurugan, S.; Riisager, A.; Dumesic, J. A.; Taarning, E. Green Chem. 2012, 14, 702-706.

(69) Moreau, C.; Durand, R.; Pourcheron, C.; Razigade, S. Ind. Crops Prod. 1994, 3, 85-90. 
(70) Kim, S. B.; You, S. J.; Kim, Y. T.; Lee, S. ; Lee, H.; Park, K.; Park, E. D. Korean J. Chem. Eng. 2011, 28, 710-716.

(71) Tsobanakis, P.; Meng, X.; Abraham, T. W. U.S. Patent 0221457, 2005.

(72) West, R. M.; Holm, M. S.; Saravanamurugan, S.; Xiong, J.; Beversdorf, Z.; Taarning, E.;

Christensen, C. H. J. Catal. 2010, 269, 122-130.

(73) Lew, C. M.; Rajabbeigi, N.; Tsapatsis, M. Microporous Mesoporous Mater. 2012, 153, 55-58.

(74) Martínez Velarde, A.; Bartl, P.; Nießen, T. E. W.; Hoelderich, W. F. J. Mol. Catal. A: Chem. 2000, 157, 225-236.

(75) Sheldon, R. A. Stud. Surf. Sci. Catal. 1991, 59, 33-54.

(76) Moreau, C.; Durand, R.; Peyron, D.; Duhamet, J.; Rivalier, P. Ind. Crops Prod. 1998, 7, 95-99.

(77) Lourvanij, K.; Rorrer G. L. Appl. Catal., A. 1994, 109, 145-165.

(78) Moreau, C.; Durand, R.; Roux, A.; Tichit, D. Appl. Catal., A. 2000, 193, 257-264.

(79) D’Hondt, E.; Van de Vyver, S.; Sels, B. F.; Jacobs, P. A. Chem. Commun. 2008, 6011-6012.

(80) Román-Leshkov, Y.; Chheda, J. N.; Dumesic, J. A. Science 2006, 312, 1933-1937.

(81) Mirescu, A.; Berndt, H.; Martin, A.; Prüsse, U. Appl. Catal., A 2007, 317, 204-209.

(82) Lopez-Orozco, S.; Inayat, A.; Schwab, A.; Selvam, T.; Schwieger, W. Adv. Mater. 2011, 23, 2602-2615.

(83) Tosheva, L.; Valtchev, V. P. Chem. Mater. 2005, 17, 2494-2513.

(84) Chal, R.; Gerardin, C.; Bulut, M.; van Donk, S. ChemCatChem 2011, 3, 67-81.

(85) Pérez-Ramírez, J.; Christensen, C. H.; Egeblad, K.; Christensen, C. H.; Groen, J. C. Chem. Soc. Rev. 2008, 37, 2530-2542.

(86) Pérez-Ramírez, J.; Mitchell, S.; Verboekend, D.; Milina, M.; Michels, N. -L.; Krumeich, F.; Marti, N.; Erdmann M. ChemCatChem 2011, 3, 1731-1734.

(87) Verboekend, D.; Pérez-Ramírez, J. Catal. Sci. Technol. 2011, 1, 879-890.

(88) Verboekend, D.; Vilé, G.; Pérez-Ramírez, J. Adv. Funct. Mater. 2012, 22, 916-928. 
(89) Christensen, C. H.; Schmidt, I.; Carlsson, A.; Johannsen, K.; Herbst, K. J. Am. Chem. Soc. 2005, $127,8098-8102$.

(90) Yang, J.; Yang, J. Y.; Zhou, Y.; Wei, F.; Lin, W. G.; Zhu J. H. J. Hazard. Mater. 2010, 179, 1031-1036.

(91) Jin, M. J.; Taher, A.; Kang, H. J.; Choi, M.; Ryoo, R. Green Chem. 2009, 11, 309-313.

(92) Lee, D. -H.; Choi, M.; Yu, B. -W.; Ryoo, R. Chem. Commun. 2009, 74-76.

(93) Højholt, K. T.; Vennestrøm, P. N. R.; Tiruvalam, R.; Beato, P. Chem. Commun. 2011, 47, 12864-12866.

(94) Milina, M.; Mitchell, S.; Domínguez Trinidad, Z.; Verboekend, D.; Pérez-Ramírez, J. Catal. Sci. Technol. 2012, 2, 759-766.

(95) Xin, H.; Koekkoek, A.; Yang, Q.; van Santen, R.; Li, C.; Hensen, E. J. M. Chem. Commun. 2009, 7590-7592.

(96) Kustova, M.; Kustov, A.; Rasmussen, S. B.; Christensen, C. H. Appl. Catal., B 2006, 67, 60-67.

(97) Transition from batch to continuous processing (2009), Competence manager process intensification DSM Pharmaceutical Products, Geleen, The Netherlands, http://www2.fhi.nl/pharmaceuticals/archief/2009/images/dsm.pdf (accessed February 2012).

(98) Kreutzer, M. T.; Du, P.; Heiszwolf, J. J.; Kapteijn, F.; Moulijn, J. A. Chem. Eng. Sci. 2001, 56, 6015-6023.

(99) Boodhoo, K.V.K.; Jachuck, R.J. J. Appl. Therm. Eng. 2000, 20, 1127-1146.

(100) Harvey, A.P.; Mackley, M.R.; Stonestreet, P. Ind. Eng. Chem. Res. 2001, 40, 5371-5377.

(101) Huang, H. J.; Ramaswamy, S.; Tschirner, U. W.; Ramarao, B. V. Sep. Purif. Technol. 2008, 62, $1-21$.

(102) Meng, X. S.; Tsobanakis, P.; Malsam, J.; Abraham, T. U.S. Patent 0027342, 2007.

(103) Paspek, S. C.; Every, W. A. U.S. Patent 4230888, 1980.

(104) Dumesic, J. A.; Román-Leshkov, Y.; Chheda, J. N. U.S. Patent 0033188, 2008. 
(105) Torres, A. I.; Daoutidis, P.; Tsapatsis, M. Energy Environ. Sci. 2010, 3, 1560-1572.

(106) Mascal, M.; Nikitin, E. B. Angew. Chem., Int. Ed. 2008, 47, 7924-7926.

(107) Gürbüz, E. I.; Wettstein, S. G.; Dumesic, J. A. ChemSusChem, 2012, 5, 383-387.

(108) Kröger, M.; Prüsse, U.; Vorlop, K. -D. Top. Catal. 2000, 13, 237-242.

(109) Arora, M. B.; Hestekin, J. A.; Snyder, S. W.; Martin, Er. J. St.; Lin, Y. J.; Donnelly, M. I.; Sanville Millard, C. Sep. Sci. Technol. 2007, 42, 2519-2538.

(110) Snyder, M. A.; Tsapatsis, M. Angew. Chem., Int. Ed. 2007, 46, 7560-7573. 
Table 1. Main zeolites and zeotypes used in the liquid-phase conversion of bio-based molecules under mild conditions and most prominent catalytic data obtained.

\begin{tabular}{|c|c|c|c|c|c|c|c|c|c|c|c|}
\hline Framework & Zeolite & $\mathrm{Si} / \mathrm{M}^{\mathrm{a}}$ & Reaction & Reactant & Desired product & Conv. & Selec. & Feed conc. & Reusability & Active sites & Ref. \\
\hline \multirow{10}{*}{ BEA } & \multirow{7}{*}{ Sn-beta ${ }^{b}$} & \multirow{7}{*}{$\begin{array}{l}96^{\mathrm{c}} \\
125^{\mathrm{d}}\end{array}$} & \multirow{3}{*}{ isomerization } & glucose & fructose & $56^{\mathrm{c}}$ & $75^{\mathrm{c}}$ & $45 \mathrm{wt} \%$ & 4 times & \multirow{7}{*}{ Lewis acid } & 63,64 \\
\hline & & & & xylose & xylulose & $77^{\mathrm{d}}$ & $27^{\mathrm{d}}$ & $10 \mathrm{wt} \%$ & 3 times & & 65 \\
\hline & & & & $\overline{\text { DHA }}$ & lactic acid & $99^{\mathrm{d}}$ & $90^{d}$ & $3 \mathrm{wt} \%$ & & & 66 \\
\hline & & & \multirow{4}{*}{ retro-aldolization } & fructose & \multirow{3}{*}{ methyl lactate } & $99^{\mathrm{d}}$ & $44^{\mathrm{d}}$ & $10 \mathrm{wt} \%$ & 6 times & & 67 \\
\hline & & & & glucose & & $99^{\mathrm{d}}$ & $43^{\mathrm{d}}$ & $10 \mathrm{wt} \%$ & 6 times & & 67 \\
\hline & & & & sucrose & & $99^{\mathrm{d}}$ & $64^{\mathrm{d}}$ & $10 \mathrm{wt} \%$ & 6 times & & 67 \\
\hline & & & & $\begin{array}{l}\text { xylose, arabinose, } \\
\text { galactose, glucose, } \\
\text { mannose }\end{array}$ & methyl lactate & $24-99^{d}$ & $0-62^{\mathrm{d}}$ & $3 \mathrm{wt} \%$ & n.a. & & 68 \\
\hline & \multirow{3}{*}{ H-beta } & 15 & \multirow{3}{*}{ dehydration } & fructose & 5-HMF & 75 & 44 & $3 \mathrm{wt} \%$ & n.a. & \multirow{5}{*}{$\begin{array}{l}\text { Brønsted } \\
\text { acid }\end{array}$} & 69 \\
\hline & & 25 & & xylose & furfural & 90 & 45 & $3 \mathrm{wt} \%$ & n.a. & & 70 \\
\hline & & n.a. & & $3-\mathrm{HPA}$ & acrylic acid & n.a. & $71^{\mathrm{e}}$ & $3 \mathrm{wt} \%$ & n.a. & & 71 \\
\hline \multirow{8}{*}{ MFI } & \multirow{3}{*}{ H-ZSM-5 } & \multirow{3}{*}{25} & \multirow{2}{*}{ dehydration } & fructose & 5-HMF & 82 & 56 & $3 \mathrm{wt} \%$ & n.a. & & 69 \\
\hline & & & & xylose & furfural & 90 & 48 & $3 \mathrm{wt} \%$ & n.a. & & 70 \\
\hline & & & \multirow{4}{*}{ isomerization } & DHA & lactic acid & 99 & 22 & $3 \mathrm{wt} \%$ & n.a. & \multirow{4}{*}{ Lewis acid } & 72 \\
\hline & \multirow{3}{*}{ Sn-silicalite } & \multirow{3}{*}{125} & & glucose & fructose & 9 & 44 & $10 \mathrm{wt} \%$ & n.a. & & 73 \\
\hline & & & & xylose & xylulose & 40 & 48 & $10 \mathrm{wt} \%$ & n.a. & & 73 \\
\hline & & & & DHA & lactic acid & 98 & 66 & $10 \mathrm{wt} \%$ & n.a. & & 73 \\
\hline & \multirow{2}{*}{ TS-1 } & 46 & \multirow{2}{*}{ oxidation } & glucose & gluconic acid & 27 & 12 & n.a. & n.a. & \multirow{2}{*}{ redox } & 74 \\
\hline & & n.a. & & 5-HMF & $2,5 \mathrm{DFF}$ & n.a. & $25^{\mathrm{e}}$ & n.a. & n.a. & & 75 \\
\hline \multirow{7}{*}{ FAU } & \multirow{3}{*}{$\mathrm{H}-\mathrm{Y}$} & 15 & \multirow{3}{*}{ dehydration } & fructose & 5-HMF & 57 & 54 & $3 \mathrm{wt} \%$ & n.a. & \multirow{3}{*}{ Lewis acid } & 69 \\
\hline & & 15 & & xylose & furfural & 51 & 82 & $2 \mathrm{wt} \%$ & n.a. & & 76 \\
\hline & & 6.5 & & glucose & formic acid & 100 & 35 & $12 \mathrm{wt} \%$ & n.a. & & 77 \\
\hline & $\overline{\mathrm{Na}-\mathrm{X}}$ & 1 & \multirow{2}{*}{ isomerization } & glucose & fructose & 20 & 86 & $9 \mathrm{wt} \%$ & 1 time & \multirow{2}{*}{ Lewis acid } & 78 \\
\hline & $\mathrm{H}-\mathrm{Y}$ & 6 & & DHA & lactic acid & 99 & 71 & $3 \mathrm{wt} \%$ & n.a. & & 73 \\
\hline & $\overline{\text { Ti-Y }}$ & n.a. & oxidation & glucose & gluconic acid & 23 & 28 & n.a. & 3 times & redox & 74 \\
\hline & $\mathrm{Pt} / \mathrm{Na}-\mathrm{Y}$ & n.a. & $\begin{array}{l}\text { dehydration } \\
\text { hydrogenation }\end{array}$ & glycerol & 1,2-propanediol & 85 & 64 & $20 \mathrm{wt} \%$ & n.a. & $\begin{array}{l}\text { acid }+ \\
\text { metal }\end{array}$ & 79 \\
\hline \multirow{3}{*}{ MOR } & & 11 & debydration & fructose & 5-HMF & 76 & 91 & $3 \mathrm{wt} \%$ & n.a. & Brønsted & 69 \\
\hline & H-mordenite & 11 & dehydration & xylose & furfural & 37 & 90 & $2 \mathrm{wt} \%$ & n.a. & acid & 76 \\
\hline & & 10 & isomerization & DHA & lactic acid & 99 & 39 & $3 \mathrm{wt} \%$ & n.a. & Lewis acid & 72 \\
\hline FER & $\mathrm{H}$-ferrierite & 20 & dehydration & xylose & furfural & 80 & 44 & $3 \mathrm{wt} \%$ & n.a. & $\begin{array}{l}\text { Brønsted } \\
\text { acid }\end{array}$ & 70 \\
\hline
\end{tabular}

${ }^{a} \mathrm{M}=\mathrm{Al}$ for H-beta, H-ZSM-5, H-Y, NaX, NaY, H-mordenite, H-ferrierite, $\mathrm{M}=\mathrm{Sn}$ for Sn-beta and Sn-silicalite, and M = Ti for TS-1 and Ti-Y. ${ }^{\mathrm{b}} \mathrm{Ti}-\mathrm{ZZr}-/ \mathrm{Al}-/ \mathrm{Si}$-beta have also been employed in order to demonstrate the role of Lewis acidity but the conversion and selectivity values are lower than for Sn-beta. ${ }^{\mathrm{c}, \mathrm{d}} \mathrm{Si} / \mathrm{Sn}$ ratios. ${ }^{\mathrm{e}} \mathrm{Yield}$. 


\section{Figures captions}

Figure 1. Total consumption of oil in the United States compared to the potential harvested biomass divided into its main uses. Reproduced with permission of Wiley-VCH Verlag from ref. 10.

Figure 2. Routes for the production of chemicals from fossil feedstocks (left to center) and biomass (right to center).

Figure 3. Illustration of the "product-targeted" approach in chemicals production from biomass. (a) Manufacture of acrylic acid: routes followed in the petrochemical industry (left to center) versus envisaged routes from bio-derived resource (right to center), and (b) preparation of ethylene glycol and adipic acid from biomass. Ethylene glycol case illustrates the "drop-in" strategy, as the preparation route takes advantage of the existing petrochemical technology from a certain stage on, while adipic acid exemplifies the "substituting" strategy as the preparation route is completely different from the current petro-based one.

Figure 4. (a) Platform molecules as defined by Bozell and Petersen. ${ }^{24}$ (b) The furan platform is exemplified with the case of 5-hydroxymethylfurfural (5-HMF). The products of proven marketable potential that can be directly derived and which illustrate the "emerging" strategy are represented.

Figure 5. Main catalyst families employed in the conversion of bio-derived molecules described in term of suitability to perform different types of reaction (orange boxes) versus main benefits and drawbacks (green boxes).

Figure 6. Intrinsic properties of purely microporous zeolites and additional features that can be incorporated by means of post-synthetic modification and functionalization.

Figure 7. DHA conversion (green bars) and LA selectivity (blue bars) over conventional and postsynthesis modified H-ZSM-5 (CBV3024E, Zeolyst International, Si/Al = 15) and H-USY (CBV720, 
Zeolyst International, $\mathrm{Si} / \mathrm{Al}=15)$ zeolites. Modification was achieved by alkaline treatment as reported in refs. 77 and 78. Conditions: $W_{\text {cat }}=80 \mathrm{mg}, c_{\mathrm{DHA}}=3 \mathrm{wt} . \%$, water solvent, $T=140^{\circ} \mathrm{C}, t=6 \mathrm{~h}$.

Figure 8. (a) Illustration of the biphasic reactor patented by Dumesic et al. ${ }^{104}$ for the continuous production of HMF by dehydration of fructose (figure adapted from refs. 80 and 105). The system comprises: (i) a CSTR, in which the HMF formed in the aqueous phase (bottom) migrates into the organic phase (top) according to its repartition coefficient, (ii) an evaporator, which serves to purify HMF and to recycle the organic phase, and (iii) an extractor, used to recover the fraction of HMF remaining in the aqueous phase. (b) Scheme of the biphasic reactor proposed by Kröger et al. ${ }^{108}$ for the conversion of fructose into 2,5-furandicarboxylic acid (FDCA). The reactor is composed of two compartments separated by a porous membrane and respectively containing the aqueous and an organic phase. Fructose is dehydrated to HMF over an acidic resin in water. In view of its smaller size only HMF is allowed to transfer to the organic phase through the membrane. In this medium an oxidation catalyst $(\mathrm{Pt}-\mathrm{Bi} / \mathrm{C})$ is present which converts $\mathrm{HMF}$ to FDCA. 
U.S. crude oil consumption

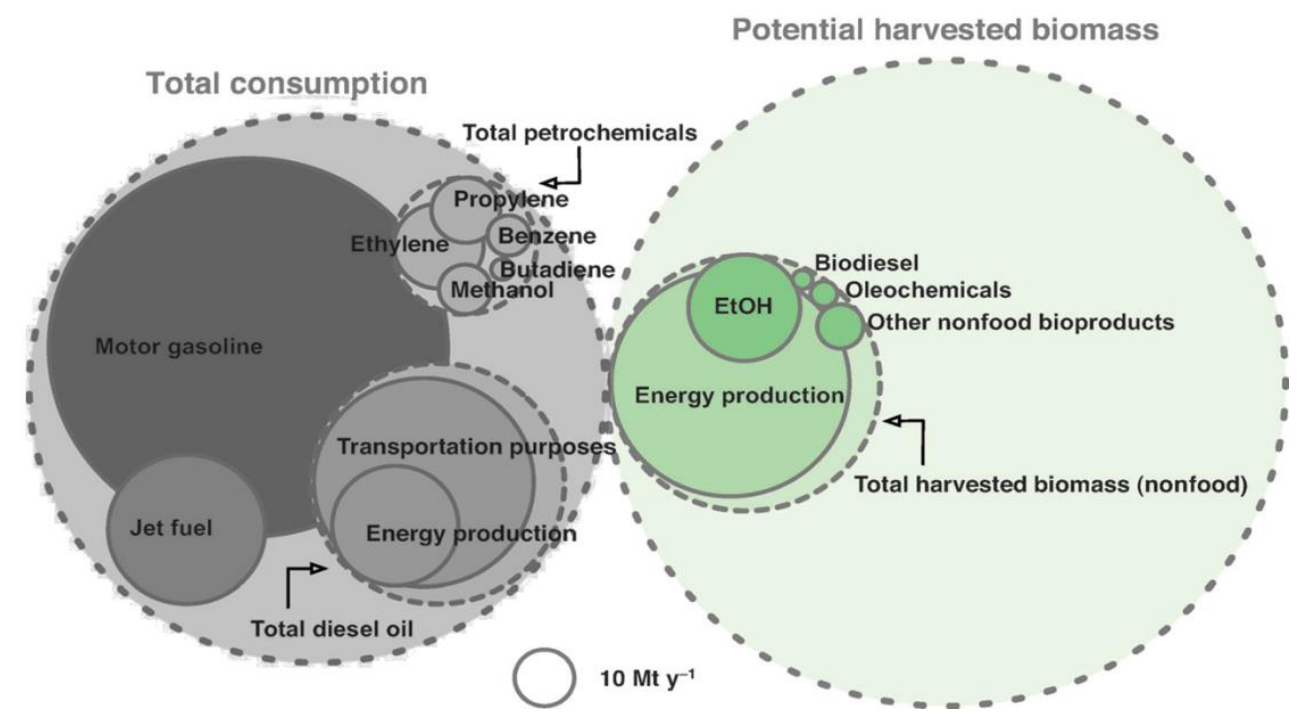

Figure 1 


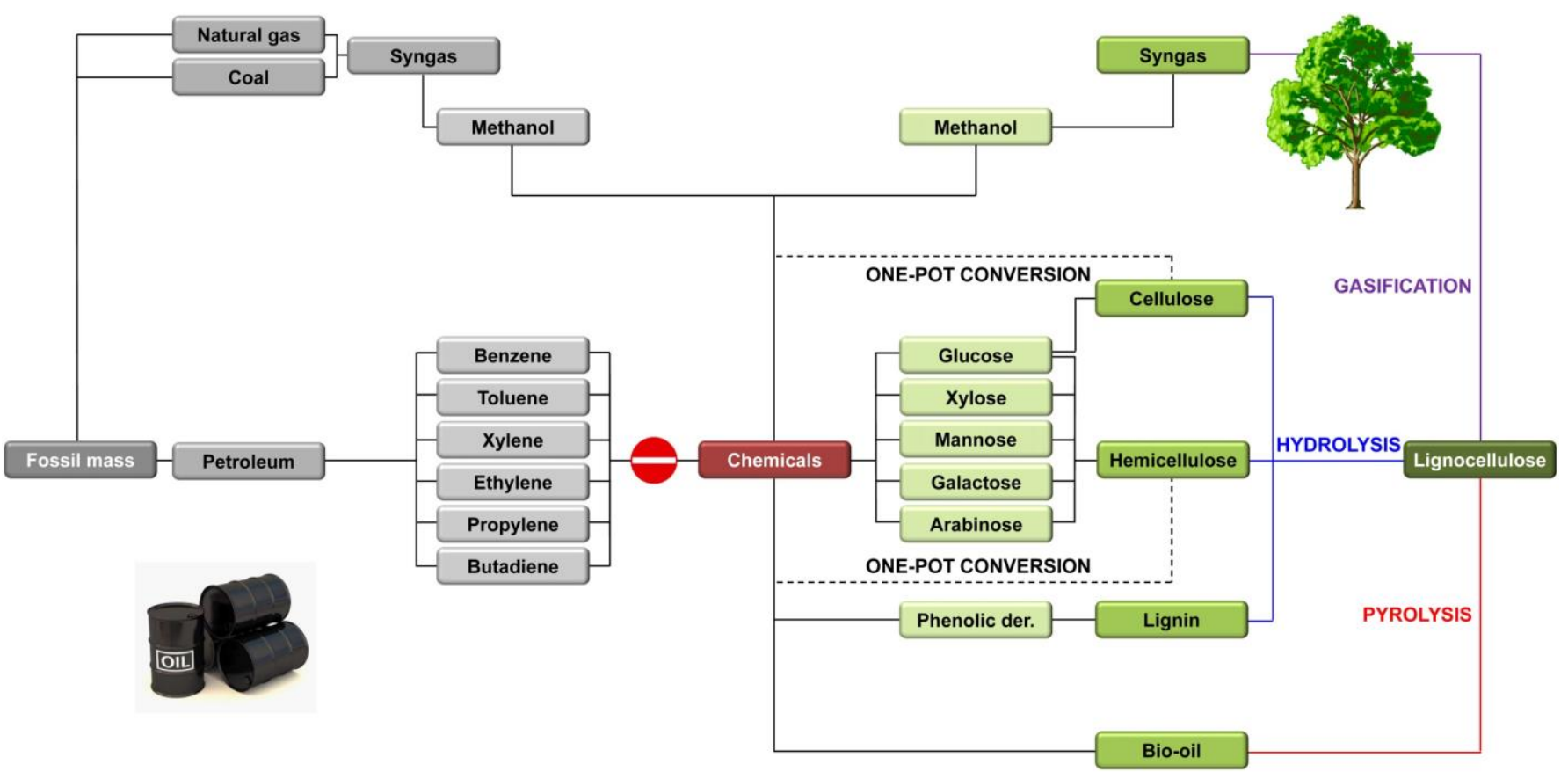

Figure 2 
(a)

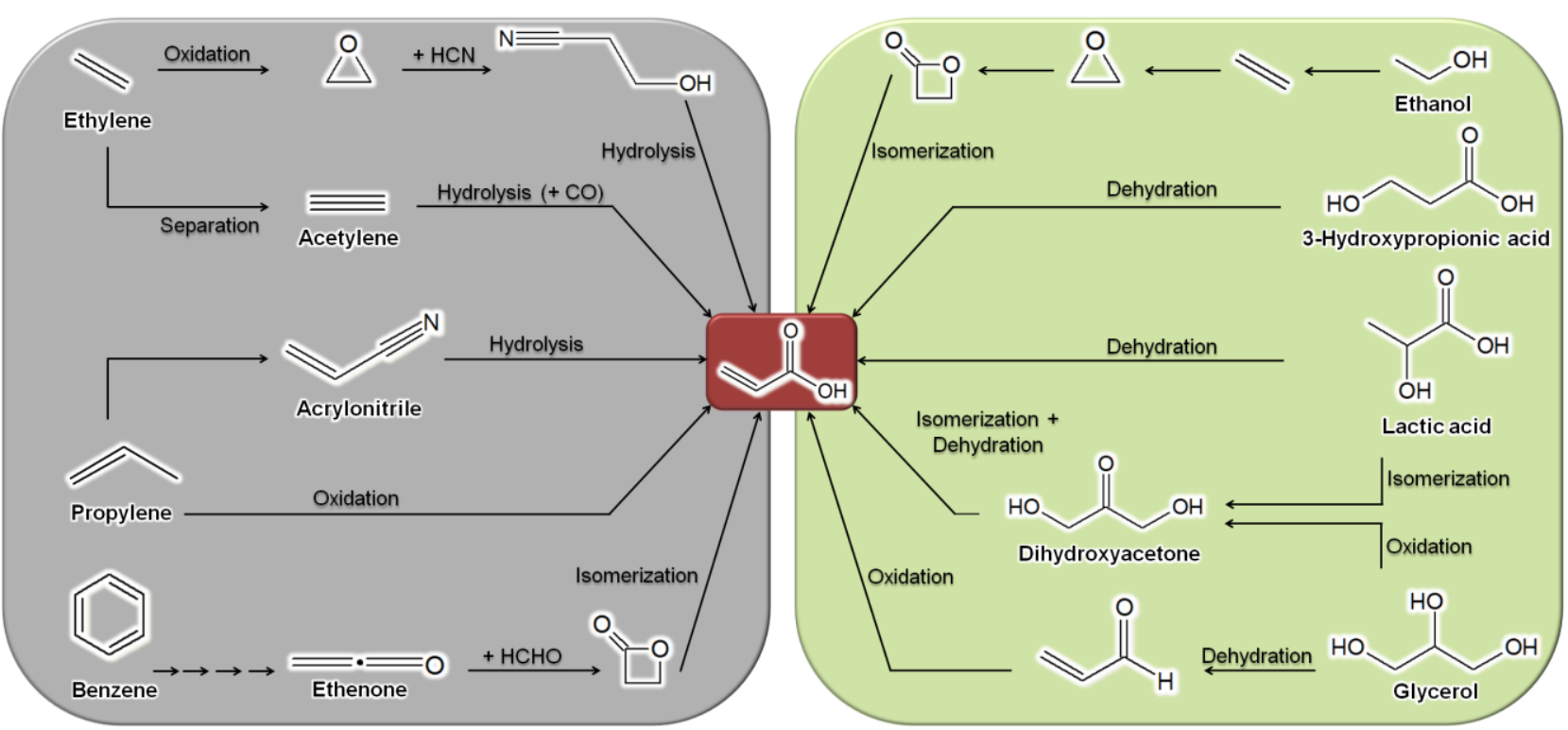

(b)

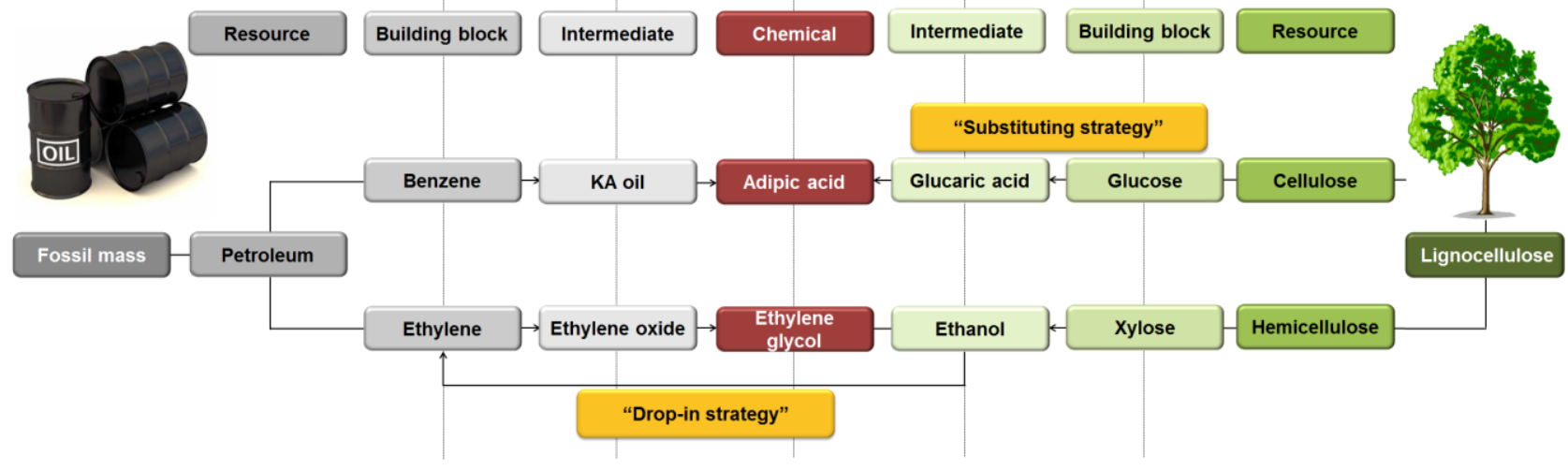

Figure 3 
(a)

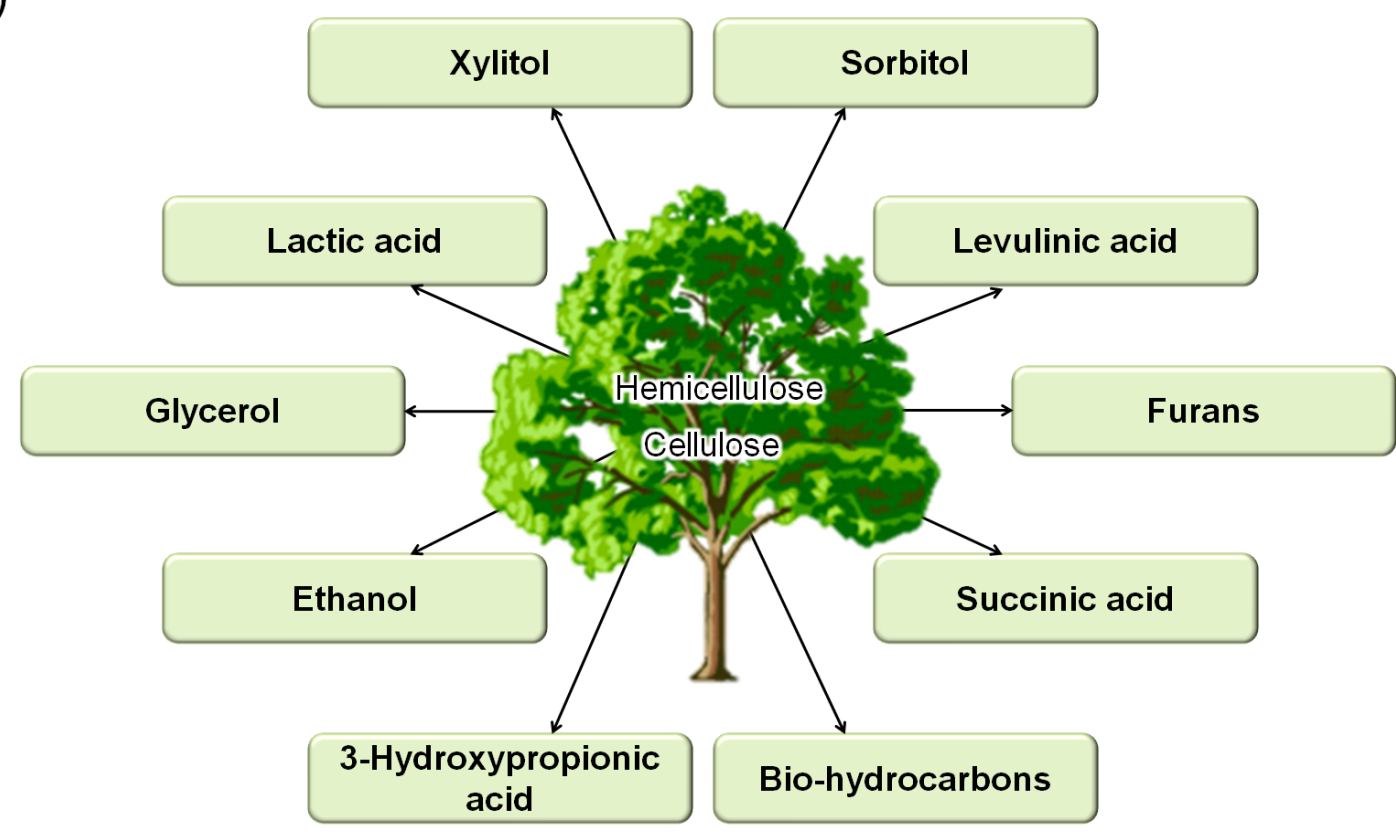

(b)

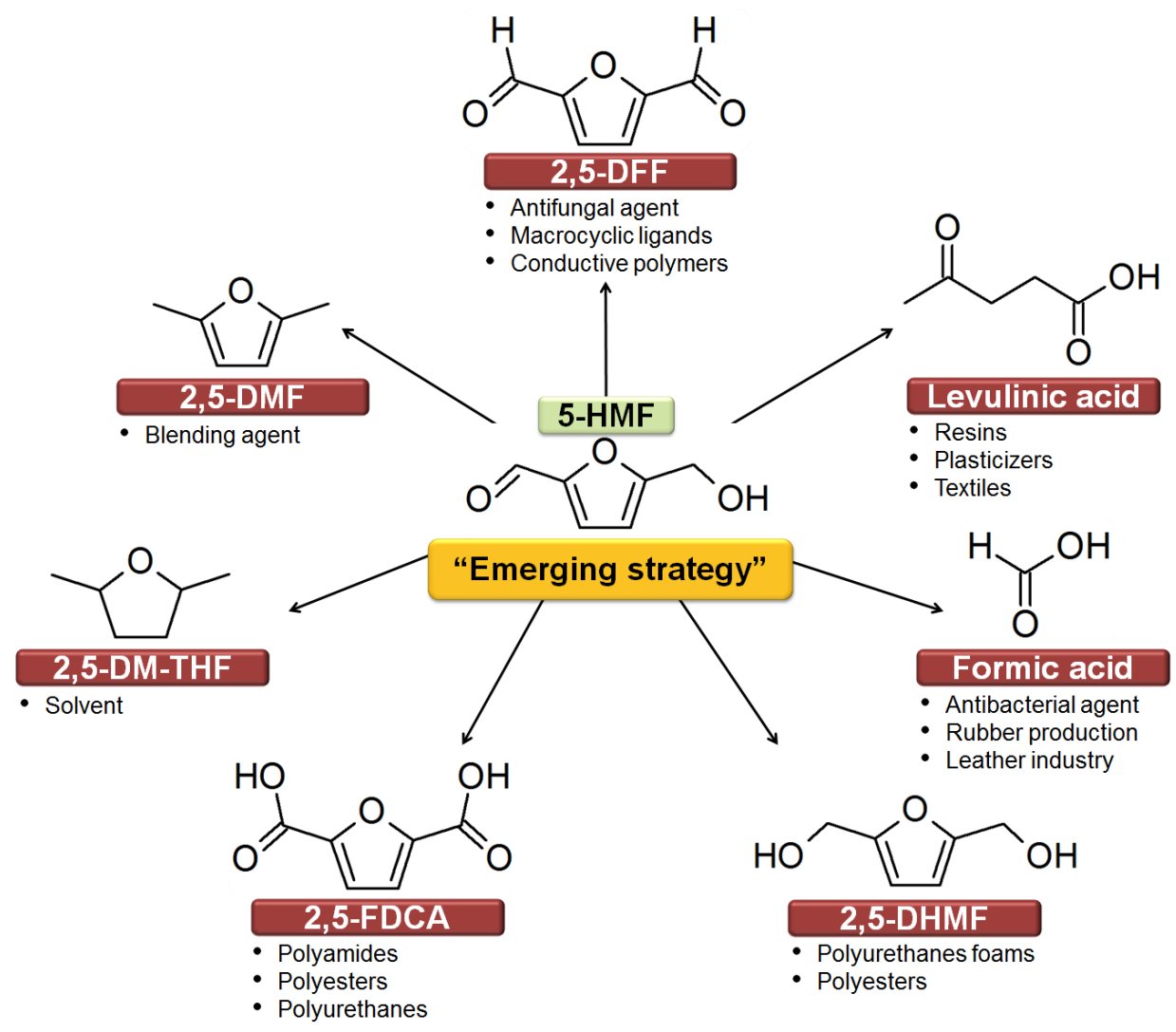

Figure 4 


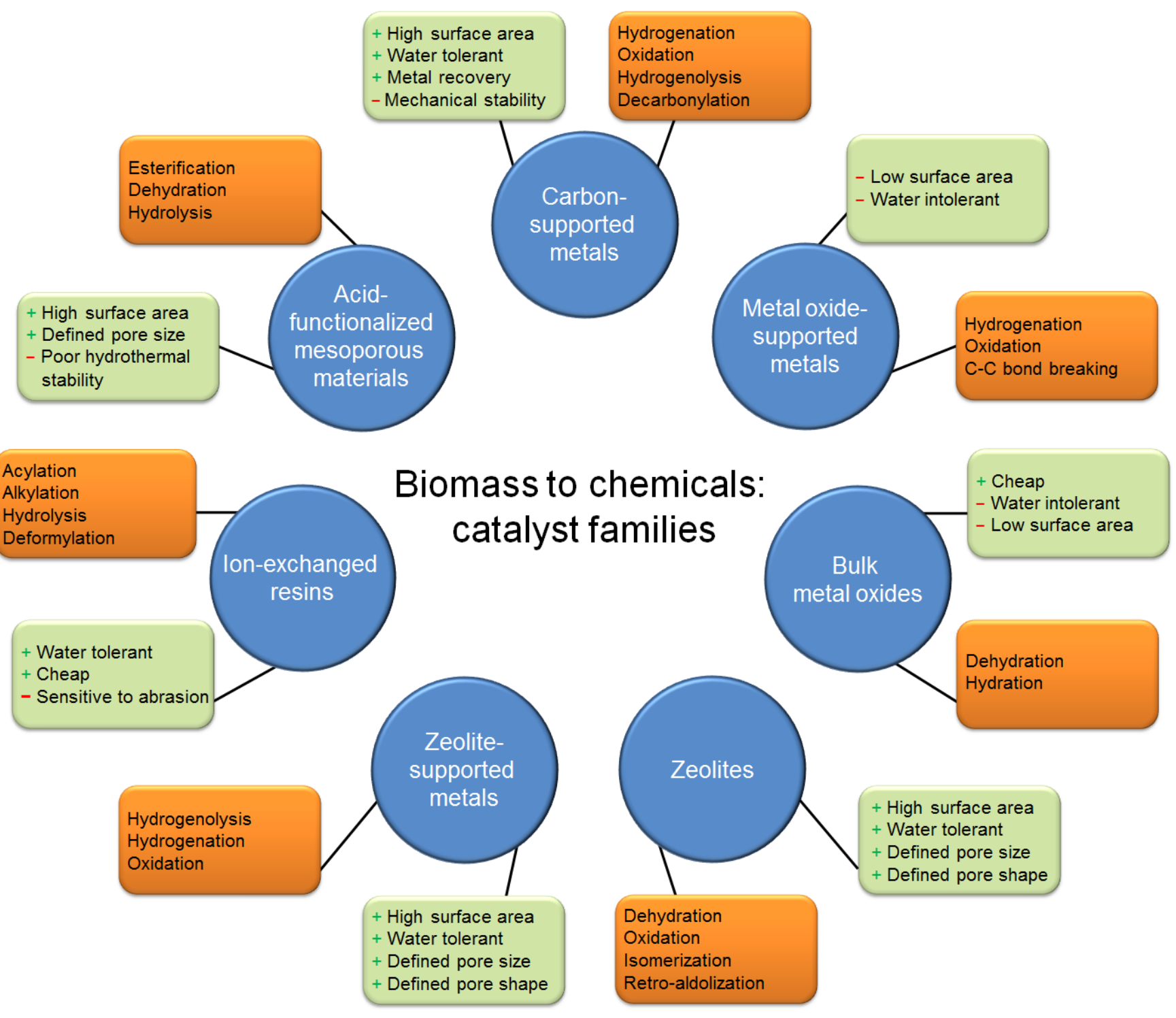

Figure 5 


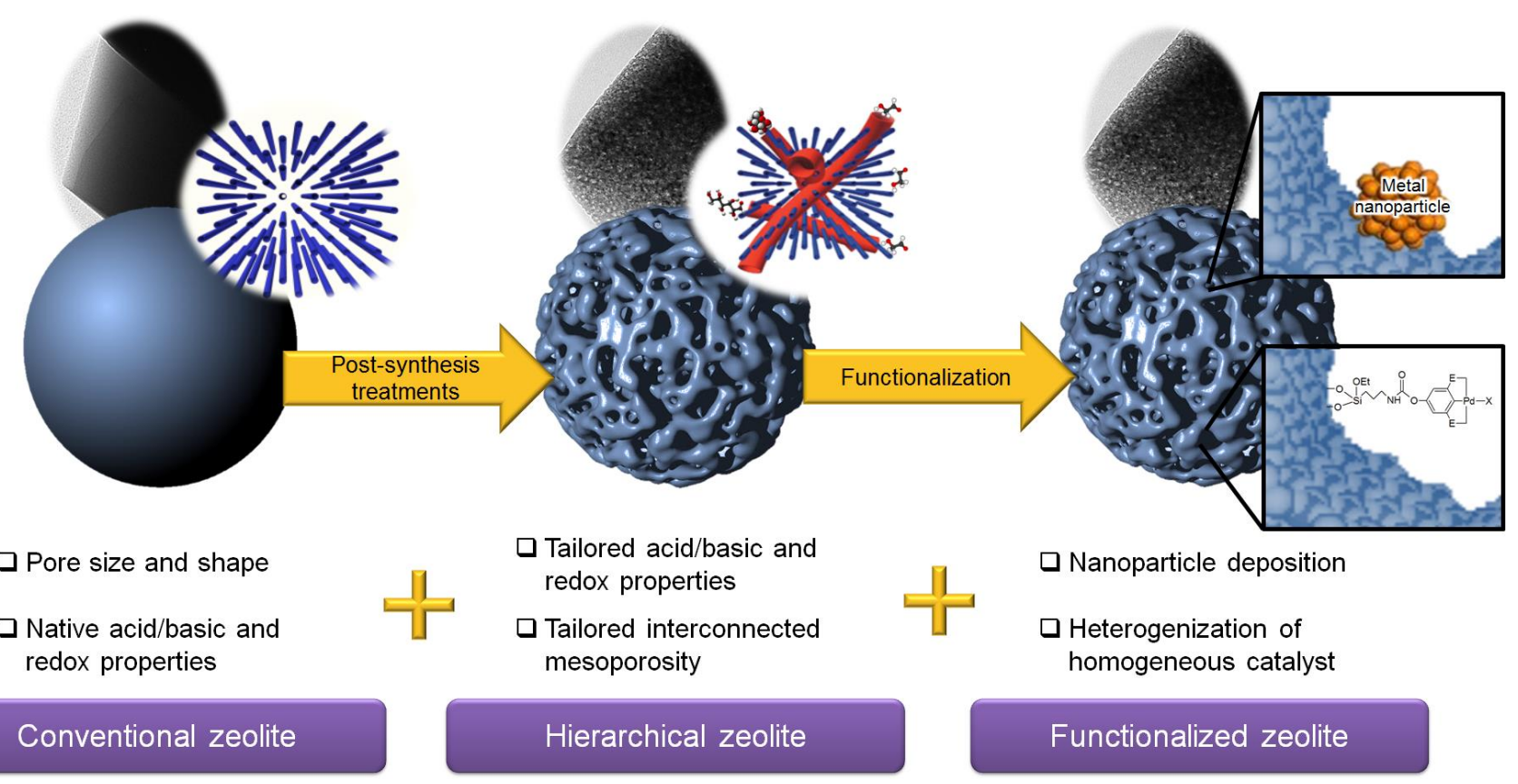

Figure 6 


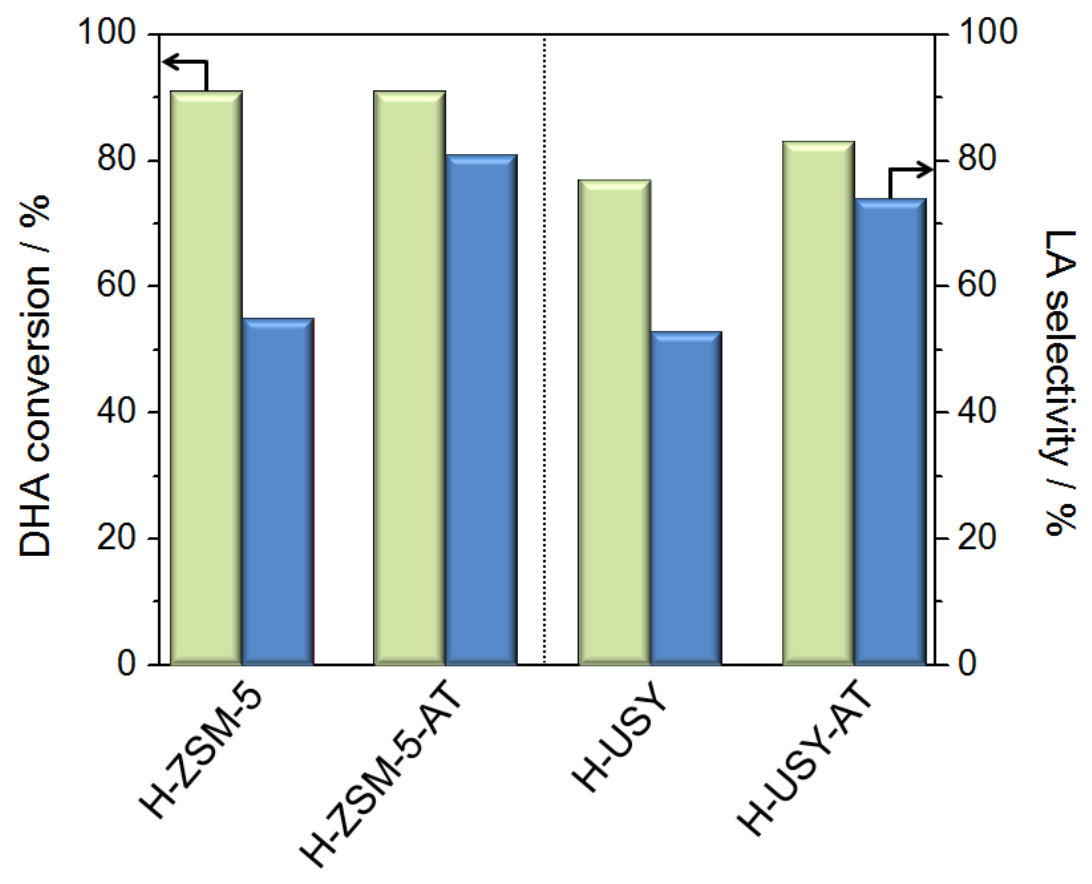

Figure 7 
(a)

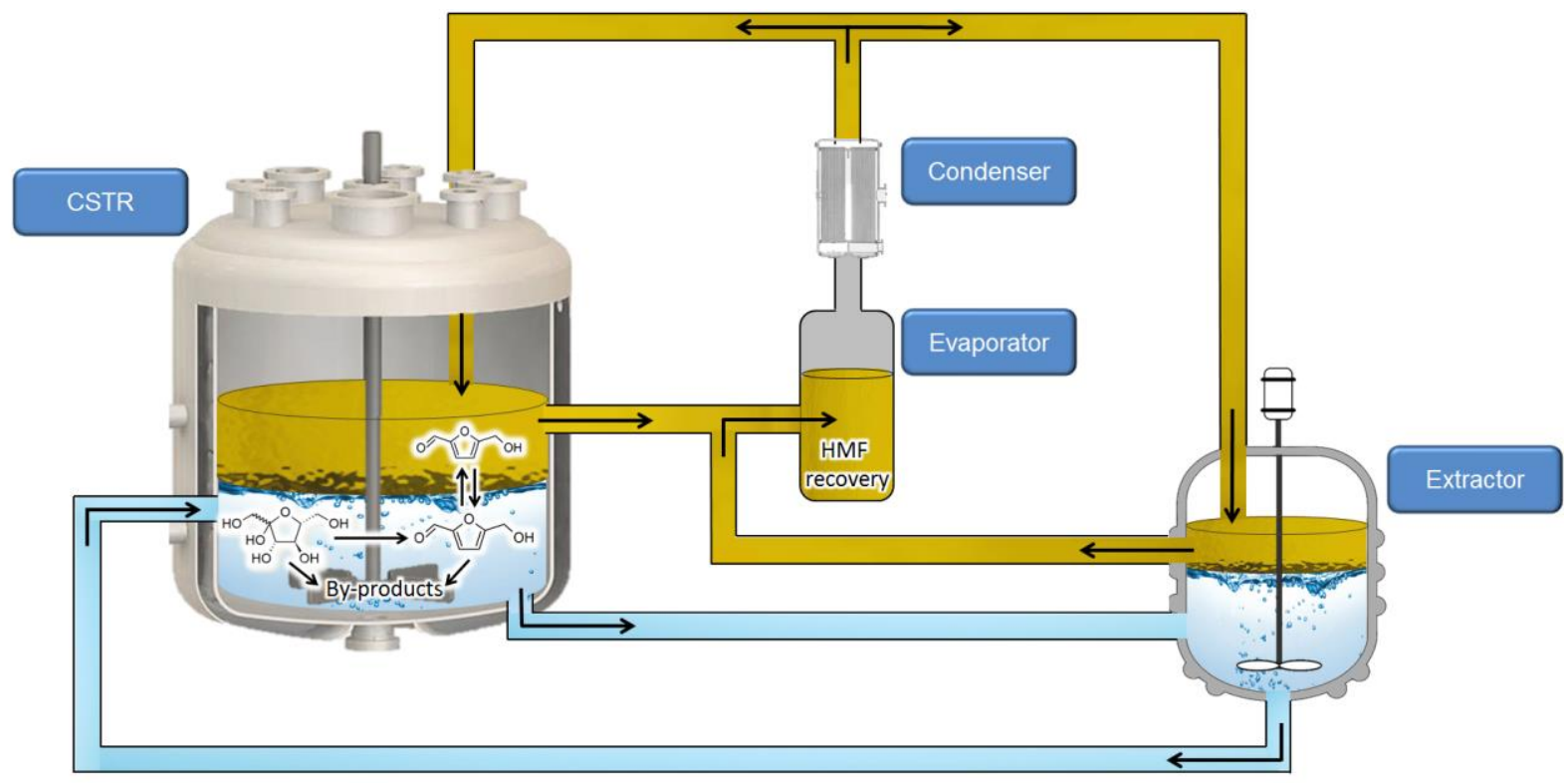

(b)

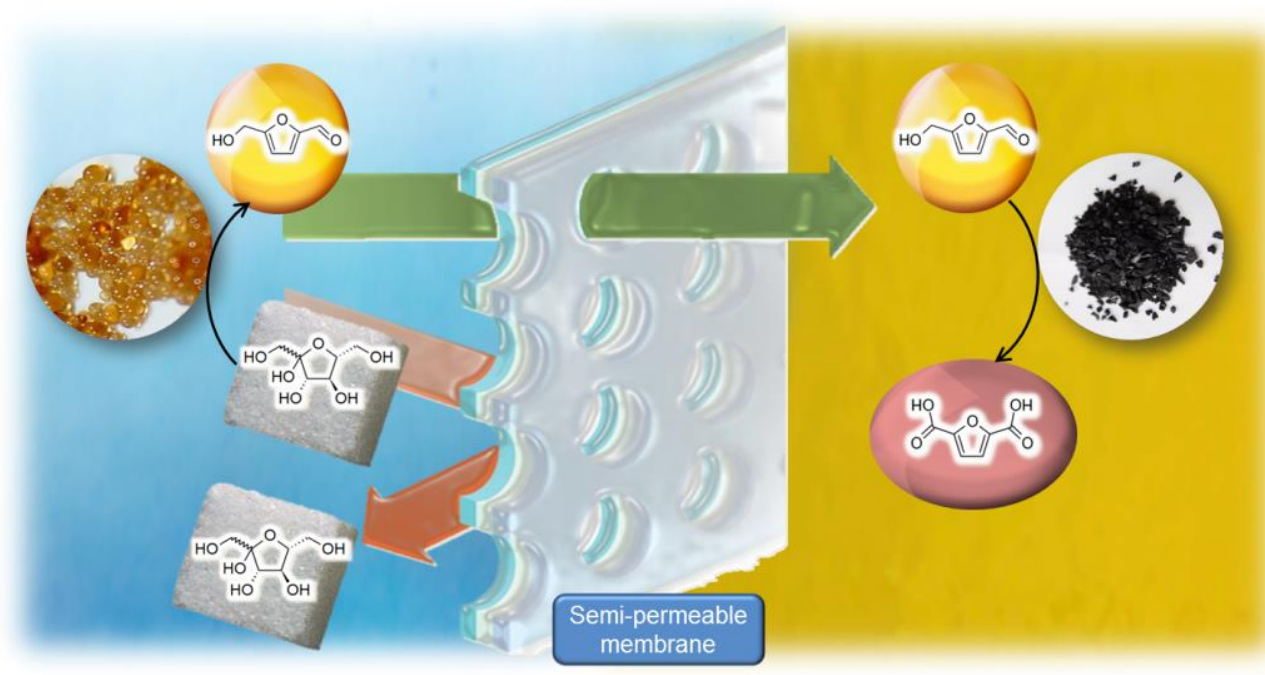

Figure 8 


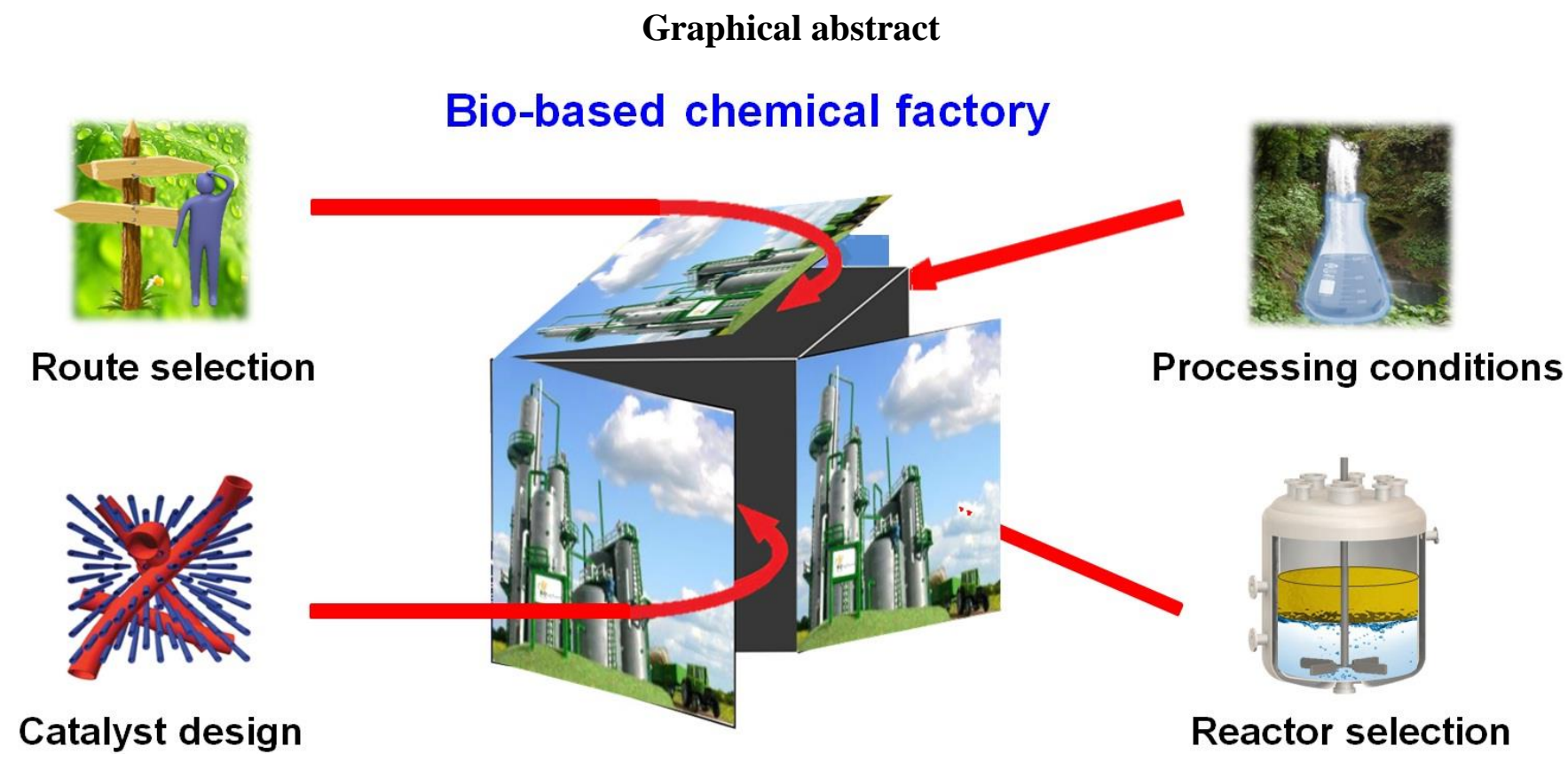

